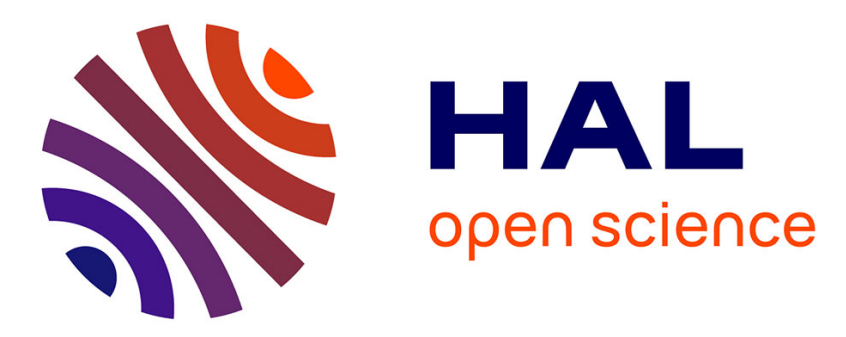

\title{
Unraveling the charge transfer/electron transport in mesoporous semiconductive TiO2 films by voltabsorptometry
}

Christophe Renault, Lionel Nicole, Clément Sanchez, Cyrille Costentin, Véronique Balland, Benoit Limoges

\section{To cite this version:}

Christophe Renault, Lionel Nicole, Clément Sanchez, Cyrille Costentin, Véronique Balland, et al.. Unraveling the charge transfer/electron transport in mesoporous semiconductive TiO2 films by voltabsorptometry. Physical Chemistry Chemical Physics, 2015, 17 (16), pp.10592-10607. 10.1039/C5CP00023H . hal-02400591

\section{HAL Id: hal-02400591 \\ https://hal.science/hal-02400591}

Submitted on 9 Dec 2019

HAL is a multi-disciplinary open access archive for the deposit and dissemination of scientific research documents, whether they are published or not. The documents may come from teaching and research institutions in France or abroad, or from public or private research centers.
L'archive ouverte pluridisciplinaire HAL, est destinée au dépôt et à la diffusion de documents scientifiques de niveau recherche, publiés ou non, émanant des établissements d'enseignement et de recherche français ou étrangers, des laboratoires publics ou privés. 


\title{
Unraveling the charge transfer/electron transport in mesoporous semiconductive $\mathrm{TiO}_{2}$ films by voltabsorptometry
}

\author{
Christophe Renault ${ }^{a}{ }^{2}$ ionel Nicole ${ }^{b}$ Clément Sanchez,${ }^{b}$ Cyrille Costentin,${ }^{{ }^{a} *}$ \\ Véronique Balland, ${ }^{{ }^{a}, *}$ and Benoît Limoges ${ }^{a_{1} *}$
}

\begin{abstract}
In this work, we demonstrate that chronoabsorptometry and more specifically cyclic voltabsorptometry are particularly well suited techniques for acquiring a comprehensive understanding of the dynamics of electron transfer/charge transport within a transparent mesoporous semiconductive metal oxide film loaded with a redox-active dye. This is illustrated with the quantitative analysis of the spectroelectrochemical responses of two distinct heme-based redox probes adsorbed in highly-ordered mesoporous $\mathrm{TiO}_{2}$ thin films (prepared from evaporation-induced self-assembly, EISA). On the basis of a finite linear diffusion-reaction model as well as the establishment of the analytical expressions governing the limiting cases, it was possible to quantitatively analyse, predict and interpret the unusual voltabsorptometric responses of the adsorbed redox species as a function of the potential applied to the semiconductive film (i.e., as a function of the transition from an insulating to a conductive state or viceversa). In particular, we were able to accurately determine the interfacial charge transfer rates between the adsorbed redox species and the porous semiconductor. Another important and unexpected finding, inferred from the voltabsorptograms, is an interfacial electron transfer process predominantly governed by the extended conduction band states of the EISA $\mathrm{TiO}_{2}$ film and not by the localized traps in the bandgap. This is a significant result that contrasts to those previously observed for dye-sensitized solar cells formed of randomly sintered $\mathrm{TiO}_{2}$ nanoparticles, a behaviour that was ascribed to a particularly low density of localized surface states in $\mathrm{EISA} \mathrm{TiO}_{2}$. The present methodology also provides a unique and straightforward access to an activation-driving force relationship according to the Marcus theory, opening thus new opportunities not only to investigate the driving-force effects on electron recombination dynamics in dye-sensitized solar cells but also to study the electron transfer/transport mechanisms in heterogeneous photoelectrocatalytic systems combining nanostructured semiconductor electrodes and heterogeneous redox-active catalysts.
\end{abstract}

\section{Introduction}

Because of their high surface area and unique electrical and optical properties, transparent nanostructured $\mathrm{TiO}_{2}$ films have received considerable interest for a wide range of applications ranging from dye-sensitized solar cells ${ }^{1}$ to photo- and/or electro-catalysis, ${ }^{2}$ chemical and biochemical sensors, ${ }^{3}$ electrochromics, ${ }^{4}$ or energy storage devices (batteries, supercapacitors). ${ }^{5}$ Many of these applications rely on electro- or photo-induced electron transfer reactions of redox-active molecules adsorbed within nanoporous $\mathrm{TiO}_{2}$ films deposited on transparent conductive substrates. ${ }^{6}$ The redox functionality of these films is intimately related to the dynamic of charge transfer/electron transport across the semiconductive metal oxide which, in turn, is strongly influenced by the nanostructured morphology of the film. ${ }^{7}$ According to their $n$ - type semiconductive properties and wide electronic band gap $(3.2 \mathrm{eV}), \mathrm{TiO}_{2}$-based films turn into conductive substrates when a sufficient amount of electrons is injected into the film (e.g., by applying a cathodic potential or UV-light irradiation $)^{8}$ and insulating under reverse bias. As a function of the applied potential or light illumination, the apparent electron transport in nanostructured $\mathrm{TiO}_{2}$ loaded with redox-active molecules can thus result from an intricate combination of different physicochemical processes (Scheme 1). First, the electron transport can occur by physical motion of the adsorbed redoxactive molecules throughout the porous film up to the uncovered underlying conductive substrate (Scheme 1A). This process (characterized by a physical diffusion coefficient) implies that the electroactive molecules are not too tightly bound to the oxide surface in such a way that they can physically diffuse throughout the void volume of the porous 
structure. Second, electrons can be transported by hopping between adjacent redox molecules (Scheme 1B), a process promoted by high concentrations inside the film and fast selfexchange electron transfer. ${ }^{9,10,11}$ This second mode of electron transport, which often coexists with the first one, has been welldocumented for redox compounds as ruthenium ${ }^{12,13}$ osmium $^{14}$ polypyridyl complexes, or triaryl amines ${ }^{15}$ adsorbed in nanocrystalline $\mathrm{TiO}_{2}$ films. It is characterized by a dramatic increase in the apparent diffusion coefficient once a critical redox probe surface coverage is reached. ${ }^{14,15}$ The third possible mode of electron transport is through the conduction band of the semiconductive $\mathrm{TiO}_{2}$ matrix (Scheme 1C). It occurs only when the film is rendered sufficiently conductive by applying a cathodic potential or under photoirradiation. Because strongly linked to the performance of dye-sensitized solar cells, this mode of electron transport has been the subject of intense investigations. ${ }^{7,16,17,18,19,20,21}$ It was notably shown to be linked to the chemical potential of electrons in $\mathrm{TiO}_{2}$ and thus a function of the electron concentration injected into the film. Moreover, because mesoporous $\mathrm{TiO}_{2}$ films are usually filled with a high ionic strength electrolyte, no macroscopic electric field is present to drive the charge carriers up to the underlying conductor. Consequently, the conduction band mediated electron transport across $\mathrm{TiO}_{2}$ occurs primarily by a randomwalk diffusion process. ${ }^{16,22,23}$ This electron diffusion has also been shown ambipolar because coupled electrostatically with ions present in the electrolyte. ${ }^{22}$ Such behaviour explains why the apparent electron diffusion coefficient in nanostructured $\mathrm{TiO}_{2}$ is highly sensitive to ion concentrations and electrolyte composition. ${ }^{18,24}$ Another widely reported observation is a traplimited electron displacement due to the existence of an exponential distribution of localized trap states extending into the bandgap from the conduction band edge $\left(E_{C B}\right) .^{25,26}$ Therefore, electrons move between band-gap states via the conduction band according to a trapping/detrapping process, a phenomenon which explains the dispersive electron transport in nanoporous $\mathrm{TiO}_{2}{ }^{23,27,28}$ as well as the pronounced light intensity dependence of both the electron diffusion coefficient and electron life time in dye-sensitized nanocrystalline solar cells. ${ }^{19,28,29,30}$ Beside the different electron transport modes described above, the interfacial electron transfer at the underlying uncovered conductive substrate as well as the interfacial charge transfer taking place at the electronically conducting $\mathrm{TiO}_{2}$ surface $21,31,32$ may also affect or limit the electrochemical conversion rate of a redox probe entrapped in a porous $\mathrm{TiO}_{2}$ film.

Investigation of the electron transfer/transport in nanostructured $\mathrm{TiO}_{2}$ films is usually achieved by photoelectrochemical methods combined to a small perturbation approach (e.g., the light intensity is modulated on top of a larger one and monitored as a function of the applied potential). $7^{19}$ Electrochemically-based methods associated to a small potential perturbation superimposed to a larger one have also been proved valuable, especially for studying the electron transport in the absence of light excitation. This has been well illustrated with the electrochemical impedance spectroscopy taking advantage of a perturbation method through a small sine wave applied potential modulation, ${ }^{33,34}$ or also by measuring change in film conductivity during a small perturbation of the electrical potential applied to a $\mathrm{TiO}_{2}$ film. ${ }^{18,35}$ Although less exploited, single large electrochemical perturbation methods may also be useful with the further advantage of being directly relevant to electrochromic or supercapacitor applications. These methods include potential step chronoamperometry or cyclic voltammetry, and their corresponding spectroelectrochemical variants, i.e. chronoabsorptometry or cyclic voltabsorptometry. The usefulness of a single large perturbation method as chronoabsorptometry has been previously shown with the measurement of the apparent diffusion coefficients of redoxactive molecules adsorbed in nanocrystalline $\mathrm{TiO}_{2}$ films. ${ }^{12,14,15}$ However, these studies were systematically performed under conditions ensuring an electronically insulating film, giving thus information only on the physical and electron hopping transport. In return, few efforts have been made to characterize the electron transport/transfer in electronically conductive nanostructured $\mathrm{TiO}_{2}$ films by large electrochemical or spectroelectrochemical perturbation methods. Among these, the Meyer's group ${ }^{36}$ has taken advantage of chronoabsorptometric experiments to show compelling evidence for a conduction band mediated electron transport during the reduction of a ruthenium complex or a hemin derivative in a nanocrystalline $\mathrm{TiO}_{2}$ electrode. However, no clear relationship between the
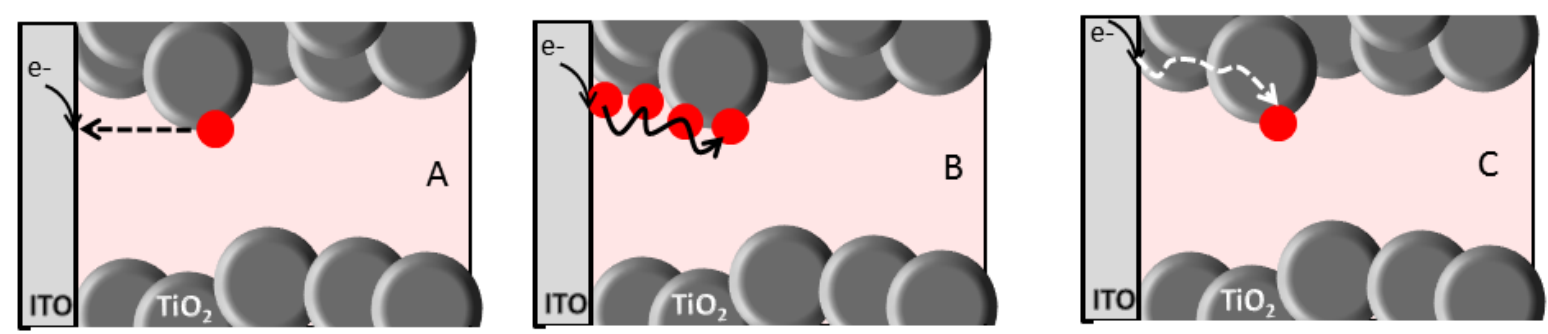

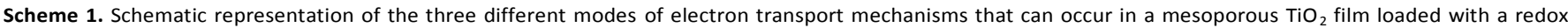
probe: (A) physical diffusion of the redox species, (B) electron transfer by hopping mechanism and (C) electron diffusion within the $\mathrm{TiO}_{2}$ material. 
measured apparent film diffusion coefficient and the applied electrical potential was proposed. Moreover, the interplays/transitions between the various charges transfer/transport modes when going from a highly insulating to a metal-like conductive $\mathrm{TiO}_{2}$ film were not investigated. Another work to mention is the one of Bisquert's group ${ }^{37}$ in which the exponential charging/discharging of electrons in nanocrystalline $\mathrm{TiO}_{2}$ films has been followed by $\mathrm{CV}$.

The main goal of the present work is to show how by using a large perturbation methods as chronoabsorptometry or more interestingly cyclic voltabsorptometry it may be possible to acquire a comprehensive understanding of the dynamic of electron transfer/charge transport within a transparent mesoporous metal oxide film loaded with a redox-active molecule. Another objective is to qualitatively and quantitatively analyse, predict and interpret the voltammetric and voltabsorptometric responses of the adsorbed redox species on account of the different modes of electron transport. In particular, it will be shown on the basis of analytical equations as well as numerical simulations of derivative cyclic voltabsorptograms how to retrieve important information on the heterogeneous charge transfer mechanism between the adsorbed redox species and the semiconducting $\mathrm{TiO}_{2}$ film, and also on the type of electronic states that controls the interfacial charge transfer.

As illustrating systems, the electrochemical oxidation/reduction rates of two heme-based redox dyes incorporated in thin transparent films of highly-ordered mesoporous $\mathrm{TiO}_{2}$ were investigated by cyclic voltammetry, chronoabsorptometry and cyclic voltabsorptometry. The main interest of chronoabsorptograms (CAs) and cyclic voltabsorptograms (CVAs) compared to the classical chronoamperograms and cyclic voltammograms (CVs) is their greater response selectivity and freedom from capacitive current. $^{38,39}$ It allowed us to entirely deconvolute the different modes of electron transport in $\mathrm{TiO}_{2}$ as a function of the applied potential (and so as a function of film conductivity). The optical- and redox-active probes we have tested are the iron(III) 5,10,15,20-tetrakis(1-methyl-4-pyridyl) porphyrin (FeTMPyP) and microperoxidase 11 (MP-11), given that: (i) thanks to their positive charges both can be strongly adsorbed into the negatively charged mesoporous $\mathrm{TiO}_{2}$ film at $\mathrm{pH} 7.0(\mathrm{pI}=5.8$ ${ }^{40}$ ), (ii) their oxidation states ( $\mathrm{Fe}^{\mathrm{III}} / \mathrm{Fe}^{\mathrm{II}}$ couple) can be easily monitored by UV-visible absorption spectroscopy, and (iii) they differ significantly by their molecular size and chemical composition. Instead of using conventional films of randomly sintered $\mathrm{TiO}_{2}$ nanoparticles, suffering thus from a relatively illdefined structure and porosity, we have chosen to work with highly-ordered mesoporous $\mathrm{TiO}_{2}$ films prepared from evaporation-induced self-assembly (EISA). ${ }^{41,42}$ Once prepared over a conductive ITO-coated glass plate, these thin films (film thicknesses ranging from 100 to $500 \mathrm{~nm}$ ) have the advantages of being highly porous, permeable, transparent, stable, free of crack, and particularly well-organized since formed by a continuous and regular 3D architecture of crystalline inorganic anatase- $\mathrm{TiO}_{2}$ phase, including a well-opened pore structure (cubic mesostructure with pore sizes of 4-10-nm). ${ }^{41,43,44}$

\section{Experimental}

\section{Chemicals and materials}

All chemicals were provided by Sigma-Aldrich except $\mathrm{TiCl}_{4}$ (Fluka) and 5,10,15,20-tetrakis(1-methyl-4-pyridyl)porphyrinFe(III) pentachloride (Cayman Chemical). All aqueous solutions were prepared with milli-Q water $\left(18.2 \mathrm{M} \Omega \mathrm{cm}^{-1}\right)$ obtained from a TKA MicroPure UV purification system. Mesoporous $\mathrm{TiO}_{2}$ thin films were prepared as previously described using the EISA method. ${ }^{42}$ Briefly, conductive ITOcoated glass plates (Aldrich, 8-12 $\square$ /square surface resistivity, $3.5 \times 2.5 \times 0.2 \mathrm{~cm}$ ) were dip-coated in a mixture of $\mathrm{TiCl}_{4}, \mathrm{H}_{2} \mathrm{O}$, $\mathrm{EtOH}$, and $\mathrm{HO}\left(\mathrm{CH}_{2} \mathrm{CH}_{2} \mathrm{O}\right)_{106}-\left(\mathrm{CH}_{2}-\mathrm{CH}\left(\mathrm{CH}_{3}\right) \mathrm{O}\right)_{70^{-}}$ $\left(\mathrm{CH}_{2} \mathrm{CH}_{2} \mathrm{O}\right)_{106} \mathrm{H}$ (Pluronic F127) (molar ratio: 1:10:40:0.006) at a withdrawal rate of $2.8 \mathrm{~mm} \mathrm{~s}^{-1}$ and relative humidity of $\mathrm{RH}=$ $20 \%$. The hybrid meso-organized thin films on ITO were next aged at $\mathrm{RH}=65 \%$ for 2 days and then gradually heated in air at $350^{\circ} \mathrm{C}$ for $3 \mathrm{~h}$. The films were finally calcinated in air at $550^{\circ} \mathrm{C}$ for $30 \mathrm{~min}$ (with a temperature ramp of $5^{\circ} \mathrm{C} / \mathrm{min}$ ). The mesoporous film thickness and pore size distribution were characterized by ellipsoporosimetry using a Woolam VASE M2000U apparatus. Film thicknesses ranging from 200 to $250 \mathrm{~nm}$ were obtained, with an average pore size of $7.5 \mathrm{~nm}$. Considering a specific surface area of $140-160 \mathrm{~m}^{2} \mathrm{~g}^{-1},{ }^{45}$ an average porosity of $40 \mathrm{vol} \%$ and a crystalline $\mathrm{TiO}_{2}$ density of $3.89 \mathrm{~g} \mathrm{~cm}^{-3}$, a specific surface area enhancement of 340-485fold per $\mu \mathrm{m}$ of film thickness can be calculated.

\section{Spectroelectrochemistry}

For spectroelectrochemical detection, a HR2000+ UV-visible diode-array spectrophotometer (Ocean Optics), equipped with optical fibers and a balanced deuterium tungsten source (Micropack), was coupled to an Autolab potentiostat PGSTAT 12 (EcoChemie) interfaced to a PC computer (GPES software). Both instruments were synchronized through an input trigger signal generated from the potentiostat, allowing thus to simultaneously recorded the change of optical absorbance during a potential step chronoamperometric or CV scan. A long pass glass color filter with a cut-off wavelength at $395 \mathrm{~nm}$ (GG395 filter, Ocean Optics), was installed between the light source and the sample to avoid photoexcitation of $\mathrm{TiO}_{2}$ network during measurements. The spectroelectrochemical measurements were performed in a home-made onecompartment three-electrode cell. ${ }^{44}$ The $\mathrm{TiO}_{2}$-film-coated ITO glass substrate was used as the working electrode, whereas a platinum wire and $\mathrm{Ag} / \mathrm{AgCl}$ electrode in $3 \mathrm{M} \mathrm{KCl}$ were used as counter and reference electrodes, respectively (i.e., $+0.21 \mathrm{~V} v s$. $\mathrm{NHE}$ at $25^{\circ} \mathrm{C}$ ). All potentials in the work were quoted to this reference electrode. The working electrode was prepared from a small rectangular piece of $0.8 \times 3.5 \mathrm{~cm}$ cut from a $\mathrm{TiO}_{2}$-film- 
coated ITO glass plate. A working area of $0.8 \mathrm{~cm}^{2}$ was delimited from one extremity of the rectangular piece by depositing an insulating layer of varnish.

The three electrodes were inserted in a $1-\mathrm{cm}$ path length quartz cell through a silicon cap that hermetically closes the cell. The working $\mathrm{TiO}_{2}$-film coated ITO electrode was positioned normal to the optical path. An additional Tygon tube (1.5-mm outer diameter) was introduced for degassing. The spectroelectrochemical cell was filled with $1.5 \mathrm{~mL}$ buffer and thoroughly freed of air by bubbling with argon (at least for halfan-hour) prior to the experiments. During the experiments, argon was continuously flowed over the solution in order to maintain the anaerobic environment and the cell was thermostated to $20^{\circ} \mathrm{C}$ using a Peltier-controlled cuvette holder (Quantum Northwest). All the experiments were carried out in an aqueous buffered of $10 \mathrm{mM}$ Hepes (pH 7.0). Experimental derivative cyclic voltabsorptograms were smoothed using a second order Savitzky-Golay algorithm.

\section{Adsorption of hemes in mesoporous EISA $\mathrm{TiO}_{2}$ films}

Incorporation of the water-soluble hemes into the highly ordered mesoporous structure of $\mathrm{TiO}_{2}$ was achieved at room temperature by simply immersing the mesoporous $\mathrm{TiO}_{2}$-coated ITO glass plates in a $10 \mathrm{mM}$ Hepes buffer ( $\mathrm{pH}$ 7.0) containing the porphyrin or MP-11 in the range of few micromolars to few tens of micromolars for a period of minutes to hours. After adsorption, the modified plates were carefully rinsed with the Hepes buffer and characterized by UV-visible absorption spectroscopy or spectroelectrochemistry in a heme-free Hepes buffer. Contributions to the spectra from the scatter and adsorption by the $\mathrm{TiO}_{2}$-coated ITO glass plates alone were removed by subtracting the blank spectra of plates recorded prior to heme adsorption.

In order to perform spectroelectrochemical experiments under conditions where Soret band absorbance remains relatively stable for at least 1-2 hours (i.e., negligible heme desorption), the following protocol was selected: (i) a first step during which a significant amount of heme is absorbed into the mesoporous $\mathrm{TiO}_{2}$ film by soaking a $\mathrm{TiO}_{2}$ film-coated ITO plate in a saturating solution of $50 \mu \mathrm{M}$ heme during $5 \mathrm{~min}$ for FeTMPyP or 1 hour for MP-11, followed by (ii) a second step of desorption during which the small fraction of weakly adsorbed heme molecules is removed by immersing the electrodes for $15 \mathrm{~min}$ in a heme-free buffer solution. The resulting modified heme-EISA $\mathrm{TiO}_{2}$ electrodes were used as a working electrode in a home-made spectroelectrochemical cell filled with a heme-free buffer solution thoroughly bubbled with argon for $30 \mathrm{~min}$ prior to the experiments.

Solution extinction coefficients of the oxidized and reduced forms of FeTMPyP and MP-11 at their maximal Soret band absorbance were determined from diluted heme solutions (5 $\mu \mathrm{M}$ in 0.1 M HEPES buffer, $\mathrm{pH} 7.0$ ) and values of $\varepsilon_{421}=10^{5}$ $\mathrm{M}^{-1} \mathrm{~cm}^{-1}$ and $\varepsilon_{403}=1.3 \times 10^{5} \mathrm{M}^{-1} \mathrm{~cm}^{-1}$ were obtained respectively. These values are in agreement with previously reported data. ${ }^{46,47}$ Solution spectra of the reduced form of FeTMPyP and MP-11 were recorded after having carefully deoxygenated the aqueous heme solution by a series of successive vacuum degassing and nitrogen bubbling, followed by the addition of 50-100 equivalents of dithionite.

\section{DCVA simulations}

To numerically simulate the DCVAs resulting from the diffusion reaction between the electrons and substrate molecules confined within the thin semiconductive film, we have used the DigiElch software ${ }^{48}$ configured in the $1 \mathrm{D}$-thinlayer simulation mode, in which the following reaction mechanism was input:

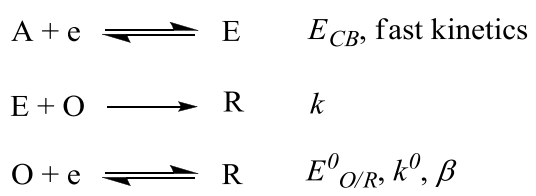

The first electrochemical reaction allows to simulate the injection of electrons from an inner boundary conductive surface $(x=0)$ to the interior of an isotropic thin-layer compartment (defined in DigiElch by a thickness $d_{f}$ of $220 \mathrm{~nm}$ ) in which the species $\mathrm{E}$ (representing the free electrons) generated from the compound A (assimilated here as the extended states into the semiconductor) linearly diffuse up to the outer boundary layer of the compartment $\left(x=d_{f}\right)$. The standard potential of this reaction is given by the conduction band potential of $\mathrm{TiO}_{2}$ (i.e., $E_{C B}=-0.78 \mathrm{~V}$ at $\mathrm{pH} 7.0$ ). The initial concentration of $\mathrm{A}$ is fixed at a value $C_{e}^{0}$ sufficiently large (i.e., $C_{e}^{0} \geq 100 \mathrm{mM}$ ) to remains approximately constant, while the diffusion coefficient of $\mathrm{E}$ is selected sufficiently high (e.g. $10^{-4} \mathrm{~cm}^{2} / \mathrm{s}$ ) to keep a nearly completely flat gradient of $\mathrm{E}$ over the whole simulation process. In order to have a Nernstian comportment at the electrode/semiconductor surface, the standard heterogeneous electron transfer rate constant of the reaction was arbitrarily fixed at a high value (e.g., $10 \mathrm{~cm} . \mathrm{s}^{-1}$ ). The second reaction of the mechanism corresponds to the homogeneous irreversible reduction of the redox substrate $\mathrm{O}$ by $\mathrm{E}$ within the thin layer compartment, while the third reaction represents the reversible one-electron transfer reaction of $\mathrm{O}$ at the inner boundary conductive surface $(x=0)$. For simulations, values of $E_{\mathrm{O} / \mathrm{R}}^{0}$ and $C_{\mathrm{O}}^{0}$ were the same as those obtained experimentally (because of possible slow desorption of heme from the porous film, $C_{\mathrm{O}}^{0}$ has been systematically recalculated from the Soret band absorbance recorded before each scan), whereas the parameters $k^{0}, D_{O}, D_{R}$ and $k C_{e}^{0}$ were iteratively adjusted until to get a set of simulated curves that correctly fit to the experimental ones. The simulations of CVs were converted into DCVA fluxes (in pmol cm $\mathrm{cm}^{-2}$ ) after subtraction of the simulated background current (in the framework of fast electron diffusion, the background CV current corresponds to an additive component of the current representing a capacitive component not observed in DCVA).

\section{Results}

1. Structure of the highly ordered mesoporous EISA $\mathrm{TiO}_{2}$ films 
The mesostructure and crystallinity of the thin films were characterized by SAXS and WAXS experiments (see Fig. S1 in Supporting Information, SI) as well as by scanning electron microscopy (Fig. 1), while the film thickness was determined by ellipsometry (average film thickness of $d_{f}=220 \pm 20 \mathrm{~nm}$ ). As expected, the mesostructure of anatase $\mathrm{TiO}_{2}$ thin films is highly ordered and corresponds to a well-opened grid-like structure. Environmental ellipsometric porosimetry analyses has confirmed the highly organized porosity of these EISA $\mathrm{TiO}_{2}$ films, displaying a porous volume of about $40 \%$ and an average pore size of $7.5 \mathrm{~nm}$ over the whole thickness.
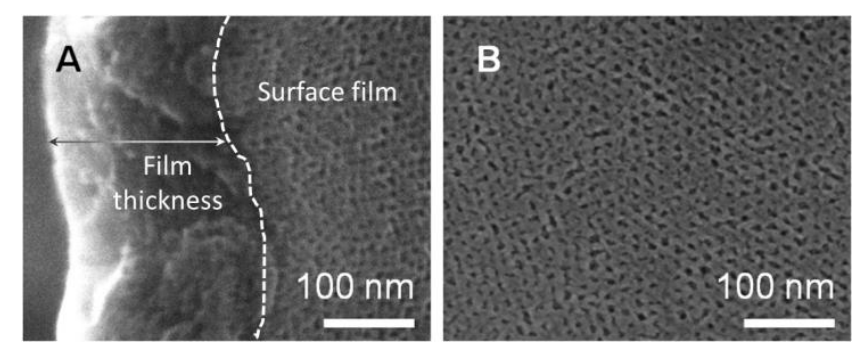

Fig. 1. SEM pictures of the side (A) and the top (B) of an $\mathrm{EISA}-\mathrm{TiO}_{2}$ film deposited on a glass substrate.

\section{Adsorption of hemes in mesoporous EISA $\mathrm{TiO}_{2}$ films}

Typical UV-visible absorption spectra of the oxidized FeTMPyP and MP-11 adsorbed in the highly ordered mesoporous $\mathrm{TiO}_{2}$ films are compared in Fig. S2 with their respective spectra in solution. Spectra of adsorbed hemes exhibit characteristic Soret bands at $427 \mathrm{~nm}$ for Fe ${ }^{\mathrm{III}} \mathrm{TMPyP}$ and $404 \mathrm{~nm}$ for $\mathrm{Fe}^{\mathrm{III}}$-MP-11 (most likely indicative of a lowspin hexacoordinated heme ${ }^{49}$ ). The total amount of hemes adsorbed can be estimated from the maximum Soret band absorbance assuming the same extinction coefficient than in solution ( $\mathrm{pH}$ 7.0). Therefore, from the spectra recorded at saturating concentrations, a maximal heme surface loading $\gamma_{F e}^{\text {sat }}$ of 2.8 and $2.0 \mathrm{nmol} \mathrm{\textrm {cm } ^ { - 2 }}$ were calculated for FeTMPyP and MP-11, respectively. This is 40-fold and 65-fold higher than predicted, respectively, for a close-packed monolayer of MP-11 or FeTMPyP on a perfectly flat surface. ${ }^{50,51,52}$ Taking into account the specific surface area of EISA $\mathrm{TiO}_{2}$ films previously determined by BET methods (i.e., 140-200 $\mathrm{m}^{2} \mathrm{~g}^{-}$ $\left.{ }^{1}\right),{ }^{45}$ these values are in relatively good agreement with the specific surface area enhancement of 78-112 calculated for the $220 \mathrm{~nm}$ film thickness. ${ }^{45}$ This suggests that the real surface area of mesoporous $\mathrm{TiO}_{2}$ film is covered by a nearly saturated monolayer of hemes. Taking into account the film thickness $(220 \mathrm{~nm})$ and porosity $(0.4)$, it corresponds to a saturating heme film concentration (i.e., concentration within the void volume of the film) of $C_{F e}^{s a t}=325 \pm 100 \mathrm{mM}$ for FeTMPyP and $C_{F e}^{\text {sat }}=$ $230 \pm 75 \mathrm{mM}$ for MP-11.

From the best fit to a Langmuir isotherm (Fig. S2), apparent binding constants $\left(K_{b}\right)$ of $1.4 \times 10^{5} \mathrm{M}^{-1}$ and $10^{6} \mathrm{M}^{-1}$ were found for FeTMPyP and MP-11, respectively. The adsorption strength of FeTMPyP is thus slightly higher than that reported for other redox-active dyes chemisorbed in nanocrystalline films of $\mathrm{TiO}_{2}$ from organic solvents (Table S1), while for MP-11 it is 10-fold higher than FeTMPyP and similar to that previously obtained by us for Cyt-c in similar $\mathrm{TiO}_{2}$ films. ${ }^{44}$

\section{Chronoabsorptometry}

After stepping the potential to a sufficiently cathodic value, characteristic spectral changes associated to the electrochemical reduction of the iron centre of FeTMPyP or MP-11 (from a formal oxidation state of III to II) were observed (Fig. S3). For each compound, the final spectrum of the reduced form as well as the difference spectrum resulting from subtraction of fully reduced and fully oxidized hemes in $\mathrm{TiO}_{2}$ films (insets of Fig. S3) were in good agreement with spectra obtained in homogeneous solution (analogous shape and amplitudes, including identical maxima and minima wavelengths). These results are in line with quantitative electrochemical reduction of $\mathrm{Fe}^{\mathrm{III}}$ TMPyP and Fe ${ }^{\mathrm{III}}-\mathrm{MP}-11$ within the film.

Dynamics of the heme redox switching in the mesoporous $\mathrm{TiO}_{2}$ films was studied by chronoabsorptometry during which the time-dependent absorbance change was monitored following a potential step. Typical experiments for $\mathrm{Fe}^{\mathrm{III}} \mathrm{TMPyP}-$ or Fe ${ }^{\text {III }}$-MP-11-loaded $\mathrm{TiO}_{2}$ electrodes after stepping the potential from +0.4 to $-0.6 \mathrm{~V}$ and back (i.e., at potential values which are well past the standard potential $E_{O / R}^{0}$ of $-0.16 \mathrm{~V}$ for FeTMPyP and -0.37 V for MP-11 in homogeneous solution) are shown in Fig. 2. A set of experiments is also reported after stepping the potential from $-0.6 \mathrm{~V}$ to open circuit. The time course absorbance changes were monitored at wavelengths corresponding to maxima in the difference spectra (i.e. at $\lambda=$ $447 \mathrm{~nm}$ for FeTMPyP and $\lambda=419 \mathrm{~nm}$ for MP-11, see inset of Fig. S3). From the value of $\Delta \varepsilon_{\lambda}=\varepsilon_{\lambda}^{\text {Red }}-\varepsilon_{\lambda}^{O x}$ of each heme in $\mathrm{TiO}_{2}\left(\Delta \varepsilon_{447}=85000 \mathrm{M}^{-1} \mathrm{~cm}^{-1}\right.$ for FeTMPyP and $\Delta \varepsilon_{419}=80$ $000 \mathrm{M}^{-1} \mathrm{~cm}^{-1}$ for MP-11), the absorbance scale in Fig. 2 can be easily converted in $\mathrm{Fe}^{\mathrm{II}}$ surface concentration of redox active hemes (i.e., $\Delta \gamma_{\mathrm{Fe}^{I I}}=\Delta A_{\lambda} / \Delta \varepsilon_{\lambda}$ in mol cm $\mathrm{cm}^{-2}$ ). Experimental data reveals complete reduction of hemes adsorbed in EISA $\mathrm{TiO}_{2}$ films within less than one second (Fig. 2A and 2A'), while on

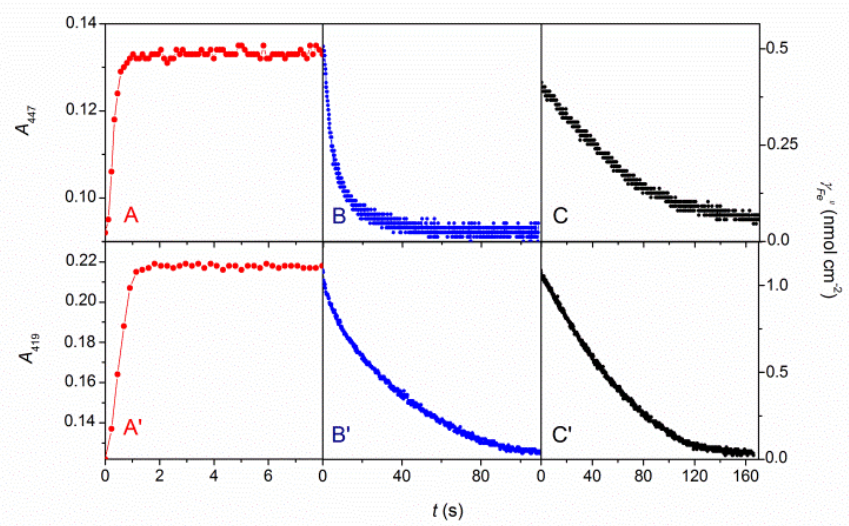

Fig. 2. Absorption changes as a function of time for (top) Fe"IMPyP-loaded EISA $\mathrm{TiO}_{2}$ electrode $\left(C_{\mathrm{Fe}}^{0} \mathrm{ll}=55 \mathrm{mM}\right)$ monitored at $447 \mathrm{~nm}$ and (bottom) Fe"III-MP-11loaded EISA $\mathrm{TiO}_{2}$ electrode $\left(C_{\mathrm{Fe}}^{0 t /}=140 \mathrm{mM}\right.$ ) monitored at $419 \mathrm{~nm}$, after stepping the potential from $\left(A, A^{\prime}\right)+0.4$ to $-0.6 V,\left(B, B^{\prime}\right)-0.6 V$ to $+0.4 V$, and $\left(C, C^{\prime}\right)-0.6 V$ to open circuit. 
stepping back the potential to the anodic direction, a much slower reoxidation rate takes place for both hemes, requiring ca. $40 \mathrm{~s}$ for a complete regeneration of $\mathrm{Fe}^{\mathrm{III}} \mathrm{TMPyP}$ (Fig. 2B), and more than $90 \mathrm{~s}$ for full recovery of the oxidized state of MP-11 (Fig. 2B'). Surprisingly, a slow spontaneous reoxidation of both $\mathrm{Fe}^{\mathrm{II}}$-hemes is also observed under open circuit and anaerobic conditions, leading to complete reoxidation over ca. $120 \mathrm{~s}$ (Fig. 2C and 2C'). It is interesting to note that, contrary to the significantly accelerated reoxidation rate of $\mathrm{Fe}^{\mathrm{II}} \mathrm{TMPyP}$ upon application of an anodic potential (compares Fig. 2B and $2 \mathrm{C}$ ), the spontaneous reoxidation rate of $\mathrm{Fe}^{\mathrm{II}}-\mathrm{MP}-11$ under open circuit is nearly the same than under the applied anodic potential (compares Fig. 2B' and 2C'). These results point out that the reoxidation of $\mathrm{Fe}^{\mathrm{II}} \mathrm{TMPyP}$ throughout the anodically polarized $\mathrm{TiO}_{2}$ is predominantly driven by an electrochemical process, while reoxidation of $\mathrm{Fe}^{\mathrm{II}}-\mathrm{MP}-11$ is on contrario almost exclusively rate limited by the spontaneous reoxidation process.

To test the influence of the applied potential on the reduction/oxidation rates of hemes in EISA $\mathrm{TiO}_{2}$ films, a series of chronoabsorptograms were recorded at different anodic and cathodic potentials (i.e., by applying a potential more negative or positive than the apparent standard potential of hemes). Fig. 3 show the time-dependent $\gamma_{F e}$ change recorded at a FeTMPyP-EISA $\mathrm{TiO}_{2}$ electrode following a series of potential steps at different cathodic/anodic values (within a potential window ranging from $-0.7 \mathrm{~V}$ to $+0.5 \mathrm{~V}$, see Fig $\mathrm{S} 4$ for additional data). The results show that the reduction rate of $\mathrm{Fe}^{\mathrm{III}} \mathrm{TMPyP}$ is strongly enhanced as the applied potential is more negative (Fig. 3A, the reaction half-life is decreased from $\sim 25 \mathrm{~s}$ at $E_{\text {appl. }}=-0.2 \mathrm{~V}$ to $\sim 150 \mathrm{~ms}$ at $E_{\text {appl. }}=-0.6 \mathrm{~V}$ ), while the reoxidation rate is almost independent both on the final anodic potential and the FeTMPyP film concentration (Fig. 3B, halftime in the range of 7-12 s). Similar experiments were also achieved at MP-11-EISA $\mathrm{TiO}_{2}$ electrodes (Fig. S5) but only in the reduction direction because, as just mentioned above, the oxidation process was observed to be mainly rate-limited by the spontaneous reoxidation of $\mathrm{Fe}^{\mathrm{II}}-\mathrm{MP}-11$ rather than by the applied anodic potential. As for the porphyrin, the reduction rate of $\mathrm{Fe}^{\mathrm{III}}$-MP-11 was observed to be exponentially accelerated as the applied potential was gradually stepped to more negative values. This behaviour is consistent with the establishment of a conduction band mediated electron transport/transfer when the semiconductive film is biased at increasingly negative potentials. ${ }^{36}$

\section{Cyclic voltammetry and derivative cyclic voltabsorptometry}

A typical set of CVs, CVAs and corresponding derivative cyclic voltabsorptograms (DCVAs) simultaneously recorded at a Fe ${ }^{\mathrm{III}}$ TMPyP-EISA $\mathrm{TiO}_{2}$ electrode are reported in Fig. 4. The blank $\mathrm{CV}$ recorded at a heme-free EISA $\mathrm{TiO}_{2}$ electrode (dashed red curve in Fig 4A) is characteristic of the charging/discharging current associated to the injection of electrons into the metal oxide film. The charging of $\mathrm{TiO}_{2}$ film starts at ca. $-0.3 \mathrm{~V}$ and exponentially grows during the forward cathodic scan and then back exponentially decreases during the reverse sweep. This behaviour is assigned to the transition from

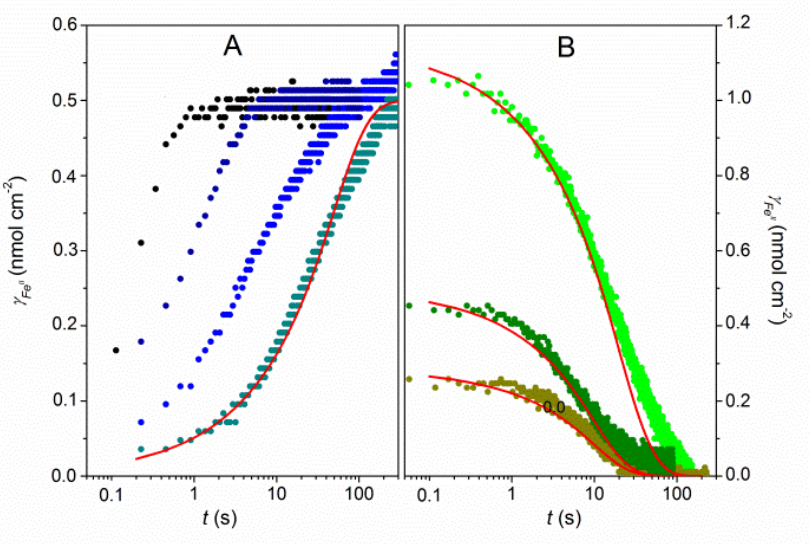

Fig. 3. (A) Time course of $\gamma_{\text {Fell }}$ changes for a Fe ${ }^{\text {III TMPyP-loaded EISA TiO }}$ electrode $\left(\gamma_{\mathrm{Fe}} \mathrm{e}^{\mathrm{It}}=5 \times 10^{-10} \mathrm{~mol} \mathrm{~cm}{ }^{-2}\right)$ after stepping the potential from $+0.4 \mathrm{~V}$ to (from right to left) $-0.2,-0.4,-0.5$ and $-0.6 \mathrm{~V}$. (B) Time course of $\gamma_{\mathrm{Fe}}$ changes for $\left[\mathrm{Fe}^{\text {IITMPyP}}{ }^{4+}\right.$-loaded EISA $\mathrm{TiO}_{2}$ electrodes after stepping the potential from -0.6 to $+0.5 \mathrm{~V}$. The electrodes were loaded with different $\gamma_{\mathrm{Fe}}$ values: (from top to down) $1.15 \times 10^{-9}, 5 \times 10^{-10}$ and $2.8 \times 10^{-10} \mathrm{~mol} \mathrm{~cm}^{-2}$. (-) Fits of eq 3 (or its complementary form) to the data using the following diffusion coefficients: (O) $4 \times 10^{-12}$, (○) $2 \times 10^{-11}$, (O) $2 \times 10^{-11}$, and (O) $10^{-11} \mathrm{~cm}^{2} \mathrm{~s}^{-1}$.

an insulating to a conductive $\mathrm{TiO}_{2}$ state. ${ }^{37}$ In the presence of FeTMPyP, the CV of the EISA $\mathrm{TiO}_{2}$ film (blue curve in Fig. 4A) shows a relatively well-defined diffusion-controlled reversible wave (centred on a formal potential of $E_{\mathrm{O} / \mathrm{R}}^{0}=-0.14$ V) superimposed to the background charging current. This reversible process is characteristic to the one-electron reduction of the adsorbed Fe ${ }^{\mathrm{III}} \mathrm{TMPyP}$, which in homogeneous solution at a bare ITO electrode and $\mathrm{pH} 7.0$ is slightly negatively shifted at $E_{\mathrm{O} / \mathrm{R}}^{0}=-0.16 \mathrm{~V}$. The attribution of the reversible wave to the redox transformation of the heme was corroborated by the simultaneously recorded CVA at $447 \mathrm{~nm}$ (blue open square symbol plot in Fig. 4B). The CVA plot effectively shows a reversible increase and decrease of the intensity as a function of potential, in good correlation with the nearly reversible anodic and cathodic peak currents on the CV. Direct comparison of CVs (preferentially subtracted from their blank capacitive current) to CVA can be facilitated by representing the flux of molecules transformed (or electron collected) per unit of time and electrode area $(\phi)$. This can be easily achieved using the following equation, which formally consists to calculate the first derivative of a CVA.

$\phi=\frac{i}{n F S}=\frac{v}{\Delta \varepsilon_{\lambda}} \frac{d \Delta A_{\lambda}}{d E}$

where here $n$ is the number of electron involved in the redox process ( $n=1$ for the $\mathrm{Fe}^{\mathrm{III}} / \mathrm{Fe}^{\mathrm{II}}$ couple), $F$ the Faraday constant, $S$ the projected area of $\mathrm{TiO}_{2}$ film $\left(\mathrm{cm}^{2}\right)$, and $v$ the scan rate $(\mathrm{V} / \mathrm{s})$. The resulting DCVA in Fig. 4C (blue open square symbol plot) is morphologically identical to the CV in Fig. 4A, except that it is free from non-faradaic response. It is worth to note that the reversible oxidation-reduction wave of the adsorbed porphyrin is located at a potential where $\mathrm{TiO}_{2}$ is definitely insulating. Therefore, the electron transport throughout the insulating $\mathrm{TiO}_{2}$ matrix should exclusively occur 


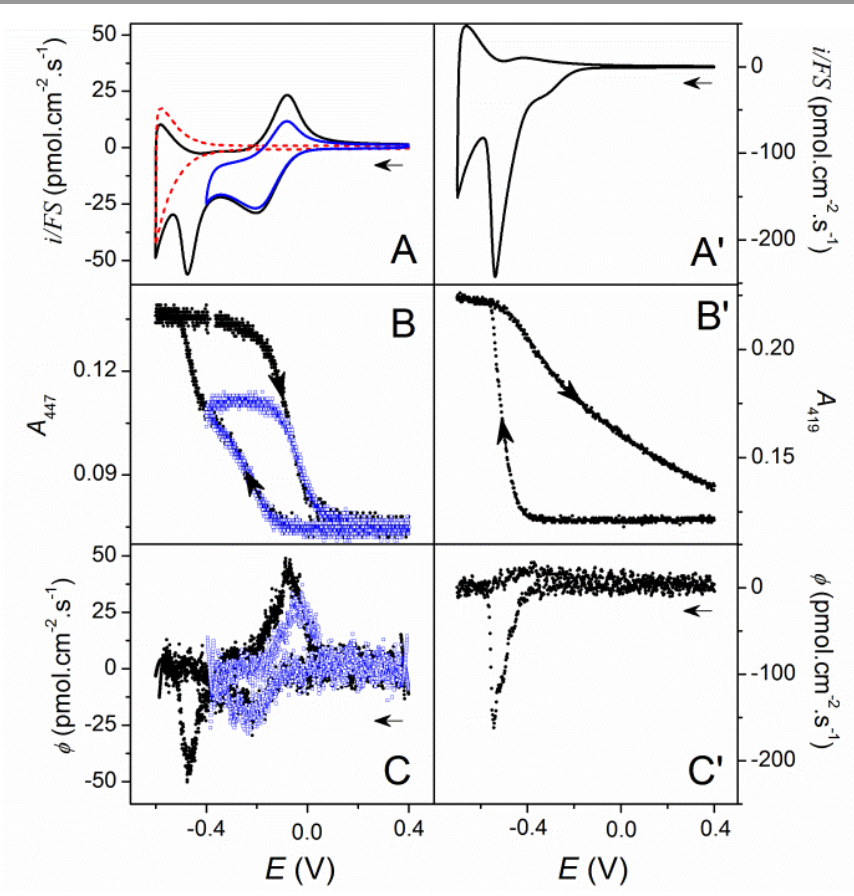

Fig. 4. $\left(A, A^{\prime}\right) C V s,\left(B, B^{\prime}\right) C V A s$ and $\left(C, C^{\prime}\right)$ DCVAs simultaneously recorded $(v=10$ $\left.m V s^{-1}\right)$ at $(A, B, C)$ a FeTMPyP- or $\left(A^{\prime}, B^{\prime}, C^{\prime}\right)$ a MP-11-loaded EISA TiO 2 electrode. During voltammetric scans, absorbance changes were monitored at 447 and 419 $\mathrm{nm}$ for FeTMPyP and MP-11, respectively. CVs and DCVAs were converted in flux density using eq 1 (see text). The dashed red CV curve in $A$ is the blank response recorded at a heme-free EISA $\mathrm{TiO}_{2}$ electrode.

by physical diffusion of FeTMPyP to the underlying conductive ITO substrate and/or by electron self-exchange (hopping) between neighbouring porphyrin molecules. This assumption was corroborated by the finding that the plot of the voltammetric cathodic peak current varies linearly as a function of $\sqrt{v}$, therefore supporting a diffusion-like process (vide infra).

Upon scanning the potential at more negative values (black plain dotted curves), a second irreversible cathodic peak at $0.47 \mathrm{~V}$ is clearly discerned on both the CV and DCVA plots. Since also present on the DCVA, this second reduction peak can be unambiguously attributed to the reduction of $\mathrm{Fe}^{\mathrm{III}}$ porphyrin adsorbed in $\mathrm{TiO}_{2}$. The shape of this irreversible wave is however unusual since exhibiting an unsymmetrical profile with a fast return to zero flux after the maximum has been reached. Another interesting observation is that the second reduction peak occurs at potentials which coincide with the exponential growth of the $\mathrm{TiO}_{2}$ film capacitance (i.e., transition from an insulating to a conductive state), hence suggesting a direct porphyrin reduction at the $\mathrm{TiO}_{2}$ interface through the conduction band electrons. During the reverse scan, a single reoxidation peak at $-0.08 \mathrm{~V}$, proportional to $\sqrt{v}$, is obtained, which is close to the standard potential of FeTMPyP and also very analogous to the reversible wave previously recorded by $\mathrm{CV}$ within a less negative potential window (i.e. in a potential zone where $\mathrm{TiO}_{2}$ remains fully insulating, blue curve).

It can also be stated from the absorbance changes in Fig. 4B that once the potential sweep is inverted just after the first reduction wave, only a fraction of the total amount of porphyrin contained in the film is reduced, while a scan past the second wave allows for complete reduction of the entire film content. Finally, after a complete cyclic scan potential, the absorbance at $447 \mathrm{~nm}$ is returned to its initial value, in agreement with that expected for a fully reversible electrochemical process.

In contrast to FeTMPyP, the CV and DCVA of MP-11EISA $\mathrm{TiO}_{2}$ electrodes (Fig. 4A'-C') show a single sharp reduction peak located at $-0.54 \mathrm{~V}$ (a potential significantly more negative than the standard potential of MP-11 in solution, i.e. $0.37 \mathrm{~V}$ ), while in the reverse scan there is no clear reoxidation peak but only a broad and ill-defined wave of small amplitude indicating a very sluggish reoxidation of $\mathrm{Fe}^{\mathrm{III}}-\mathrm{MP}-11$. The absence of a diffusion-controlled reversible wave centred on the formal potential of MP-11 on both the CV and DCVA strongly supports that MP-11 cannot move by diffusion through the insulating $\mathrm{TiO}_{2}$ nanostructure for exchanging electron to the uncovered underlying ITO substrate. It also suggests the absence of electron hopping between neighbouring MP-11. These results are in line with the larger molecular size and stronger binding affinity of $\mathrm{MP}-11$ to $\mathrm{TiO}_{2}$ compared to FeTMPyP, which taken all together would contribute to a drastic decrease of MP-11 mobility in the mesoporous $\mathrm{TiO}_{2}$ film. In the reverse scan, complete regeneration of the oxidized form of MP-11 (see CVA plot in Fig. 4B') requires several tens of seconds, which is as fast as that reported above under open circuit (Fig. 2C'). This confirms that reoxidation of $\mathrm{Fe}^{\mathrm{II}}-\mathrm{MP}-11$ in $\mathrm{TiO}_{2}$ is preferentially induced by a spontaneous reaction rather than by an electrochemical process, and so that reoxidation of $\mathrm{Fe}^{\mathrm{II}}-\mathrm{MP}-11$ by physical diffusion and/or electron hopping up to the underlying electrode is unlikely. It has to be noted that the irreversible reduction peak of Fe ${ }^{\mathrm{III}}-\mathrm{MP}-11(-0.54$ $\mathrm{V})$ is located at potential slightly more negative than the second reduction peak of FeTMPyP $(-0.47 \mathrm{~V})$. This observation is coherent with the lower $E_{\mathrm{O} / \mathrm{R}}^{0}$ of MP-11 (-0.37 V) compared to FeTMPyP $(-0.16 \mathrm{~V})$ and in line with the idea that even though the heme reduction rate is primarily controlled by the increase of the reduction power of $\mathrm{TiO}_{2}$ while the potential is raised to negative values, it remains linked to the electrochemical properties of the adsorbed redox species (vide infra).

To better understand the interplay between the different redox processes occurring during heme reduction and oxidation in $\mathrm{TiO}_{2}$ films, CVAs were recorded at various scan rates. The resulting DCVAs are shown in Fig. 5 for both FeTMPyP and MP-11. In the case of FeTMPyP it can be inferred that the magnitude of the first reduction wave is changed in proportion to the square root of the scan rate (see Fig. S6), indicating a diffusion-controlled process, while the magnitude of the second cathodic peak is strongly diminished and even nearly disappeared as the scan rates is lowered (or inversely completely prevailed at high scan rates). Such an observation reveals an intricate time-dependent interrelationship between the two reduction peaks of $\mathrm{Fe}^{\mathrm{III}} \mathrm{TMPyP}$. This is in contrast to the reduction peak of $\mathrm{Fe}^{\mathrm{III}}$-MP-11 which, at the slowest scan rates, is simply linearly increased with $v$ (Fig. S7), a behaviour characteristic of a finite thin-layer reaction where the reduction 

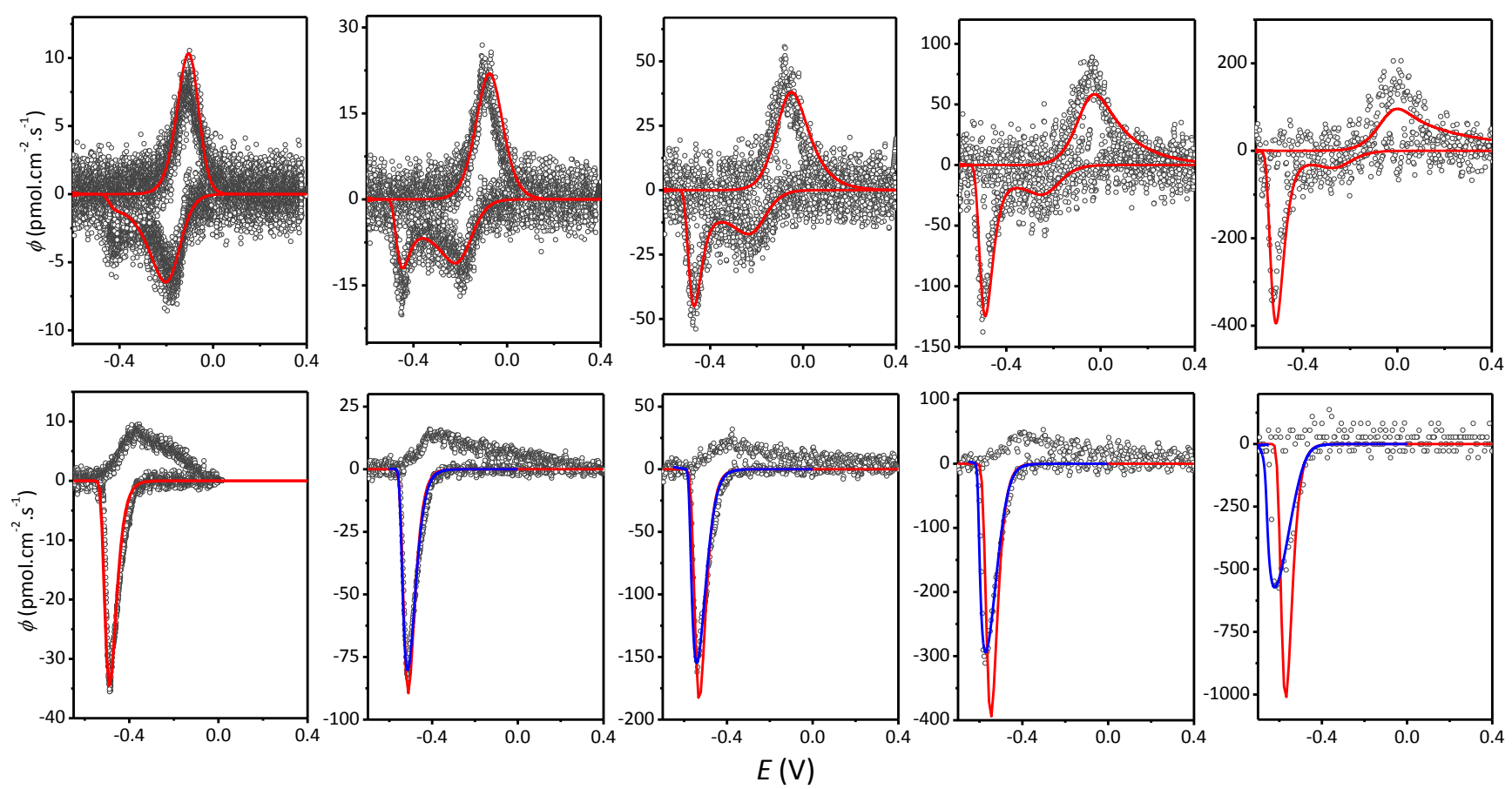

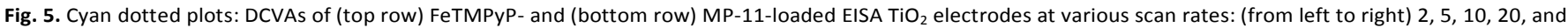

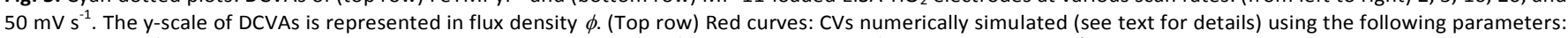

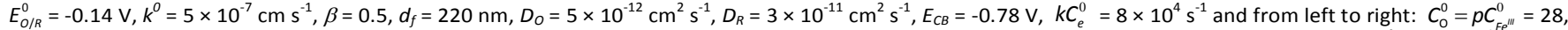

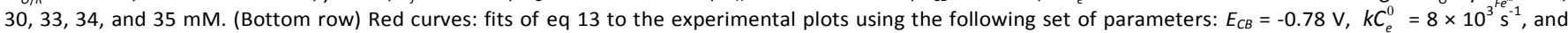

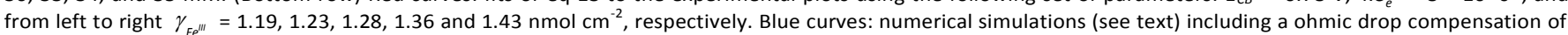
$R_{S}=1000 \Omega$

rate of $\mathrm{Fe}^{\mathrm{III}}-\mathrm{MP}-11$ in the film is neither controlled by a physical, hopping, or conduction band mediated electron transport.

\section{Discussion}

As mentioned in the introduction, the reduction/oxidation rates of redox actives molecules adsorbed within a nanoporous semiconductive $\mathrm{TiO}_{2}$ film is deeply convoluted to the different modes of charge transfer/electron transport across the film. The question now we would like to address is how to decipher between these different modes and how to rationally predict the experimental CAs, CVs and DCVAs shown in Fig. 3-5 on the basis of an appropriate model.

\section{Preliminary analysis of the electron transport/transfer when $\mathrm{TiO}_{2}$ is not conductive (i.e., at bias potentials $E>-0.3 \mathrm{~V}$ )}

The diffusion-controlled reversible wave observed on the $\mathrm{CV}$ and DCVA of the FeTMPyP-EISA $\mathrm{TiO}_{2}$ electrode, at a potential window where $\mathrm{TiO}_{2}$ is insulating, clearly evidence that, albeit adsorbed, the porphyrin can slowly diffuse throughout the $\mathrm{TiO}_{2}$ porous network before to be electrochemically oxidized/reduced at the uncovered underlying conductive ITO interface. In the case of MP-11, the absence of a reversible wave on the $\mathrm{CV}$ and DCVA close to the standard potential, and the impossibility to discern by chronoabsorptometry an electrochemical reoxidation distinctive from the slow spontaneous reoxidation occurring under open circuit allows to conclude that physical diffusion of MP-11 throughout the $\mathrm{TiO}_{2}$ network is, if effective, too slow to be observed under the experimental conditions. By quantitatively analysing the diffusion-controlled reversible wave of FeTMPyP on the DCVAs (Fig. 4 and 5) as well as the CA experiments (Fig. 3) stepped at potentials close to the porphyrin's $E_{\mathrm{O} / \mathrm{R}}^{0}$ value (i.e., at potential values where the semiconductive matrix remains in an insulating state), one would determine the apparent film diffusion coefficients of the oxidized $\left(D_{O}\right)$ and reduced $\left(D_{R}\right)$ forms of FeTMPyP. The CA responses recorded at an applied potential $>-0.3 \mathrm{~V}$ were thus analyzed in the framework of a finite linear diffusion transport along the thickness $d_{f}$ of the restricted volume of $\mathrm{TiO}_{2}$ film (considering here an isotropic film where the molecules are homogeneously distributed and able to freely diffuse throughout the entire volume of the film). This can be achieved using the following modified Cottrell equation (valid here for a reduction process) which takes into account an absorbance change instead of a current: ${ }^{53}$

$\gamma_{F e^{e}}(t)=\frac{\Delta A_{\lambda}(t)}{\Delta \varepsilon_{\lambda}}=d_{f} C_{\mathrm{O}}^{0} \frac{8}{\pi^{2}} \sum_{j=1}^{\infty}\left(\frac{1}{2 j-1}\right)^{2} \exp \left[\frac{-(2 j-1)^{2} \pi^{2} D_{O} t}{4 d_{f}^{2}}\right]$ 
Here, $\gamma_{F^{I I I}}(t)$ is the projected surface concentration of $\mathrm{Fe}^{\mathrm{II}}$ at time $t, \Delta A_{\lambda}(t)$ is the absorbance change at time $t$, and $C_{\mathrm{O}}^{0}$ is the initial concentration (in $\mathrm{mol} \mathrm{cm} \mathrm{cm}^{-3}$ ) of oxidized heme distributed homogeneously throughout the film (meaning that $C_{\mathrm{O}}^{0}=p C_{F e}^{0 I I}$ ).

The fitting of eq 2 to the experimental data allows thus to determine the apparent value of $D_{O}$ from the knowledge of $C_{F e}^{0 I I I}$ and $d_{f}$. For an oxidation, eq 2 has to be replaced by a complementary equation in which $D_{O}$ is interchanged by $D_{R}$. It is worth pointing out that eq 2 and its complementary form can be approximated at short times to recover the classical Cottrell equations. The rather good fits of eq 2 or its complementary form (both numerically solved) to the experimental CAs recorded at potentials $>-0.3 \mathrm{~V}$ (Fig. 3) suggest a proper description of the reduction/oxidation rates of porphyrin by finite linear diffusion in an isotropic film (especially at shorttime where the plot is linearly correlated to $t^{1 / 2}$, as it might be expected for a diffusion-controlled process). The apparent diffusion coefficients retrieved from the fits in Fig. 3 and from additional experiments in Fig. S4 are gathered in Table 1. The reported values of $D_{R}$ and $D_{O}$ are considerably much lower than the diffusion coefficients of FeTMPyP in aqueous solution (more than 10 000-fold lower), but of comparable magnitude to the low diffusion coefficients found for other redox species absorbed in nanocrystalline $\mathrm{TiO}_{2}$ films (e.g., a value of $1.4 \times$ $10^{-11} \mathrm{~cm}^{2} \mathrm{~s}^{-1}$ was found for the $\left[\mathrm{Os}(\mathrm{bpy})_{2}\left(4,4^{\prime}-\left(\mathrm{CO}_{2} \mathrm{H}\right)_{2}-\mathrm{bpy}\right)\right]^{2+}$ complex adsorbed at half-saturation in a nanocrystalline film of $\mathrm{TiO}_{2}{ }^{14}$ ). The low values of $D_{R}$ and $D_{O}$ are also in line with a charge transport mechanism exclusively governed by a physical diffusion of the porphyrin molecules throughout the insulating porous matrix and not by an electron hopping between adjacent porphyrin molecules. This is supported by the fact that $D_{R}$ was observed approximately constant and independent of the FeTMPyP film concentration when the latter was changed from $1 / 2,1 / 4$, to $1 / 10$ saturation (Fig. 3B and Table 1). On account of these results, hopping charge transport between adjacent porphyrin molecules is unlikely and the value of $D_{R}$ can be assimilated to the effective physical diffusion coefficient of $\mathrm{Fe}^{\mathrm{II}} \mathrm{TMPyP}$ within the film. This remark is also valid for $D_{O}$ which is slightly smaller than $D_{R}(\sim 5$-fold lower).

Table 1. Apparent diffusion coefficients of the oxidized and reduced forms of FeTMPyP in a EISA $\mathrm{TiO}_{2}$ electrode determined for different applied potentials $\left(E_{\text {appl }}>-0.3 \mathrm{~V}\right)$ and film concentrations.

\begin{tabular}{cccc}
\hline$C_{F e^{I I I}}^{0}(\mathrm{mM})$ & $E_{\text {appl }}(\mathrm{V})$ & $\begin{array}{c}D_{R} \times 10^{11} \\
\left(\mathrm{~cm}^{2} \mathrm{~s}^{-1}\right)\end{array}$ & $\begin{array}{c}D_{O} \times 10^{11} \\
\left(\mathrm{~cm}^{2} \mathrm{~s}^{-1}\right)\end{array}$ \\
\hline 130 & +0.5 & 1.0 & \\
57 & & 2.0 & \\
32 & & 2.0 & \\
\hline 57 & +0.4 & 3.0 & \\
57 & +0.3 & 1.5 & 0.4 \\
57 & +0.2 & 2.5 & \\
\hline 57 & -0.2 & & \\
\hline
\end{tabular}

The chronoabsorptograms recorded at potentials $<-0.3 \mathrm{~V}$ in Fig. 3 were not fitted to eq 2 because, at this low potential, it is no more possible to neglect the increase of $\mathrm{TiO}_{2}$ conductivity which results in a growing contribution of the conduction-band mediated electron transport/transfer. This is what we will now examine.

\section{Simple general description of the model of electron diffusion/charge transfer reaction in the film}

For modelling the different modes of electron transport/charge transfer occurring in the mesoporous $\mathrm{TiO}_{2}$ film-coated ITO, it is essential to properly describe how the electrons are injected into the semiconductive material as a function of the applied potential and how they propagate across the film. For a conventional $n$-type semiconductive material such as bulk $\mathrm{TiO}_{2}$, the increase of conductivity with the applied potential is directly linked to the free electron concentration in the conduction band $\left(n_{c b}\right)$, which is itself determined by the energy difference between the edge of the conduction band $\left(\mathrm{E}_{C B}\right)$ and the Fermi level $\left(\mathrm{E}_{F}\right)$ of the electrode (which is here assumed to be equal to $\mathrm{E}_{F}=-q E$, where $E$ is the applied potential and $q$ the elementary charge). When the semiconductive film is biased negatively, the upward shift of the Fermi level implies a change in the electron occupancy of the extended states. When electrons behave ideally, this average occupancy is expected to obey to Fermi-Dirac statistics and if the energy difference between the Fermi level and the conduction band is much larger than the thermal energy $\left(\mathrm{E}_{C B}-\mathrm{E}_{F}>k_{B} T\right)$, the density of free electrons in $\mathrm{TiO}_{2}$ can be given by the Boltzmann distribution approximation (eq 3):7, 18

$n_{c b}=N_{C} \exp \left(\frac{\mathrm{E}_{F}-\mathrm{E}_{C B}}{k_{B} T}\right)$

with $N_{C}$ the density of extended states in the conduction band, $k_{B}$ the Boltzmann constant, and $T$ the temperature. With nanoporous $\mathrm{TiO}_{2}$ films impregnated with an electrolyte, electron transport is assumed to proceed by diffusion because of the absence of significant electrical potential gradient in the film. ${ }^{22}$ Consequently, on the basis of eq 3 and considering that the injected electrons diffuse freely throughout an equivalent isotropic film of thickness $d_{f}$, it may be written that the free electron concentration $\left(C_{e}\right)$ at the ITO/semiconductive film interface $(x=0)$ follows an exponential function of the applied potential $E$ (eq 4$)$.

$\left(C_{e}\right)_{x=0}=C_{e}^{0} \exp \left[-\frac{F}{R T}\left(E-E_{C B}\right)\right]$

with $C_{e}^{0}$ the maximal electron concentration that can be injected at saturation in the conduction band of the semiconductive film. Once injected, the electrons diffuse linearly up to the outer boundary of the semiconductive film (with a constant diffusion coefficient $D_{e}$, Scheme 2). Moreover, during their travel across the film, free electrons may react irreversibly (especially if $E_{\mathrm{O} / \mathrm{R}}^{0}>E_{C B}$ ) with the adsorbed oxidized heme $\mathrm{O}$ (with a rate constant $k$ ) at the porous semiconductive/solution interface, giving finally the reduced product $\mathrm{R}$ (Scheme 2 ). In addition to the diffusion of free 


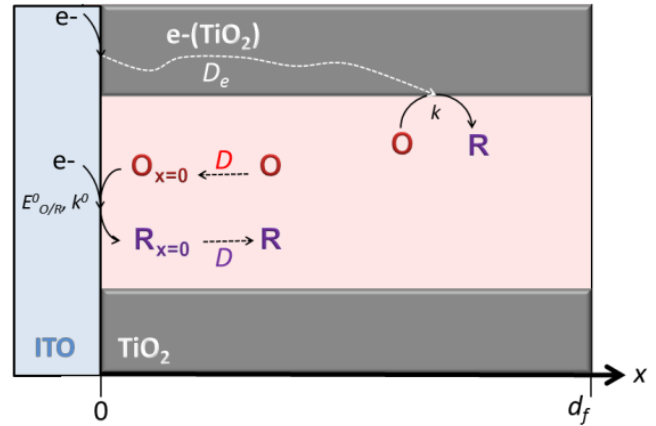

Scheme 2. The two main heterogeneous electron transfer reaction pathways involved in the reduction of species $\mathrm{O}$ considered in the simple model.

electrons from the ITO electrode to the interior of the semiconductive film, $\mathrm{O}$ and $\mathrm{R}$ are able to diffuse with a low diffusion coefficient $D_{O}$ and $D_{R}$, respectively (but neither $\mathrm{O}$ or $\mathrm{R}$ can get out of the film). Consequently, $\mathrm{O}$ can be directly reduced into $\mathrm{R}$ at the uncovered underlying ITO electrode according to an interfacial reversible one-electron transfer reaction (that may be described by a Butler-Volmer kinetics with a heterogeneous electron transfer rate constant $k^{0}$ and a transfer coefficient $\beta=0.5$ ). For sake of simplicity, the physical diffusion coefficients of $\mathrm{O}$ and $\mathrm{R}$ within the film are at first assumed to be identical (i.e. $D=D_{O}=D_{R}$ ). Substrate, product and electron transports within the film may each be likened to a finite linear diffusional transport (normal to the $x$ direction of the conductive surface) obeying the Fick's diffusional law which, in the presence of the interfacial electron transfer reaction, leads to reaction-diffusion equations given in the SI together with appropriate boundary conditions. In particular, at the underlying conductive $\mathrm{ITO} / \mathrm{TiO}_{2}$ interface, the total current density $I$ (or flux, $\phi$ ) is given by:

$$
I=I_{e}+I_{p h}\left(\text { or } \phi=\phi_{e}+\phi_{p h}\right)
$$

with

$$
\begin{aligned}
\phi_{e}=\frac{I_{e}}{F}= & -D_{e}\left(\frac{\partial C_{e}}{\partial x}\right)_{x=0} \\
\phi_{p h}=\frac{I_{p h}}{F}= & k^{0} \exp \left[-\frac{F}{2 R T}\left(E-E_{\mathrm{O} / \mathrm{R}}^{0}\right)\right] \\
& \left\{\left(C_{\mathrm{O}}\right)_{x=0}-\left(C_{\mathrm{R}}\right)_{x=0} \exp \left[\frac{F}{R T}\left(E-E_{\mathrm{O} / \mathrm{R}}^{0}\right)\right]\right\} \\
= & D\left(\frac{\partial C_{\mathrm{O}}}{\partial x}\right)_{x=0}=-D\left(\frac{\partial C_{\mathrm{R}}}{\partial x}\right)_{x=0}
\end{aligned}
$$

$I_{e}$ is the current resulting from the amount of free electrons injected into the semiconductive film and $I_{p h}$ the faradaic current arising from the electrochemical transformation of the adsorbed redox probe at the uncovered underlying ITO electrode. Note that an additional contribution to be considered is $I_{I T O}$ the capacitive current of the underlying ITO electrodes. By solving the set of reaction-diffusion equations given in the
SI using the boundary conditions, one should thus be able to calculate the theoretical CA, CV or DCVA curves. ${ }^{54}$

\section{Analysis of the CV background current in the absence of charge transfer reaction with a substrate}

CVs have been recorded at heme-free EISA $\mathrm{TiO}_{2}$ electrodes $\left(d_{f}=220 \mathrm{~nm}\right)$ for various scan rates in a Hepes buffer $(\mathrm{pH} 7.0)$ (Fig. S8 and 6) and, as expected, in the non-conductive zone of $\mathrm{TiO}_{2}(E>-0.3 \mathrm{~V})$ the capacitive current remains low, proportional to the scan rate, and nearly independent of the applied potential. At potentials $<-0.3 \mathrm{~V}$, the exponential increase of the background current during the forward scan and its decrease during the reverse scan are proportional to the scan rate. This is well-illustrated in Fig. S8 where CVs normalized to $v$ tends to overlaid at all scan rates, except for the slowest one (i.e., $2 \mathrm{mV} / \mathrm{s}$ ) for which a dissymmetry between the forward and reverse charging current is developing (vide infra). The fact that the $\mathrm{CV}$ charging current of $\mathrm{TiO}_{2}$ is proportional to $v$ and not to $\sqrt{v}$ (within the range of scan rates tested) attests that the transport of electrons by diffusion throughout the film is fast and not rate limiting under the experimental conditions, i.e. $D_{e}$ $\gg d_{f}^{2}(F v / R T)=10^{-9} \mathrm{~cm}^{2} / \mathrm{s}$ (see SI for more details). The semilogarithmic representation of the experimental forward CV scans $(0.1 \mathrm{~V} / \mathrm{s})$ in Fig. 6A shows a linear variation of $\log (I)$ with the potential from an onset potential $<-0.4 \mathrm{~V}$. An average slope of $5.7 \mathrm{~V}^{-1}$ was retrieved in agreement with that previously found by others groups for nanocrystalline films of randomly sintered $\mathrm{TiO}_{2}$ nanoparticles. ${ }^{37}$ Such behaviour can be interpreted by the presence of electron traps (or localized states) in the bandgap of the semiconductor which greatly influence the electron transport and charge transfer in mesoscopic $\mathrm{TiO}_{2}$ films (in the absence of traps a steeper slope of $17 \mathrm{~V}^{-1}$ is theoretically expected). ${ }^{19,31,37}$ According to the multipletrapping model generally used to describe such a nonideal behaviour, ${ }^{25,27,26}$ it is proposed that the localized traps are
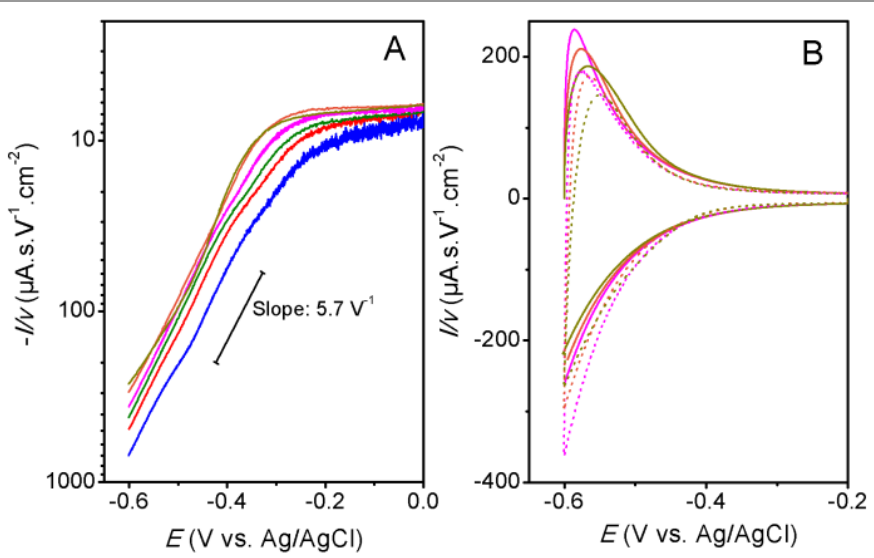

Fig. 6. CVs recorded at EISA $\mathrm{TiO}_{2}$ electrodes in Hepes buffer $(10 \mathrm{mM})$ for different scan rate $v$ : (blue) 2, (red) 5, (green) 10, (magenta) 20, (yellow) 50, (dark yellow) $100 \mathrm{mV} / \mathrm{s}$. (A) Semilogarithmic scale representation of the forward scans. (B) Simulations of (plain curves) CV blank responses at 20,50 and $100 \mathrm{mV} / \mathrm{s}$ using an exponential capacitance coupled to a series resistance $R_{S}$. The simulated curves were obtained with the following parameters: $R_{S}=1500 \Omega, \alpha F /(R T \ln 10)=5.5 \mathrm{~V}^{-1}$, $C_{\text {ITO }}=6 \mu \mathrm{F} / \mathrm{cm}^{2}$ and $C_{t}=0.1 \mu \mathrm{F} / \mathrm{cm}^{2}$. This set of parameter provides the best simulated fits to the experimental CV plots (dashed curves). 
rapidly and reversibly filed/emptied by the free electrons when the Fermi level varies. Moreover, this is achieved at rates that are much faster than the electron transport through extended states, ${ }^{55}$ but also for trap states energies that are assumed to follow an exponential distribution in the bandgap according to: $23,27,28$

$$
g\left(\mathrm{E}_{T}\right)=\frac{\alpha N_{\mathrm{T}}}{k_{B} T} \exp \left[\alpha \frac{\left(\mathrm{E}_{T}-\mathrm{E}_{C B}\right)}{k_{B} T}\right]
$$

with $\mathrm{E}_{T}$ is the energy of the trap, $N_{T}$ the total trap density and $\alpha$ a parameter that reflects the average energy of the trap states distribution below the conduction band. This leads to a density of trapped electrons that exponentially varies with the Fermi level as:

$n_{\text {trap }}=N_{\mathrm{T}} \exp \left(\alpha \frac{\mathrm{E}_{F}-\mathrm{E}_{C B}}{k_{B} T}\right)$

The total electron density in the semiconducting nanoporous film is consequently the combination of charges accumulated in both the conduction band and trap states $\left(n_{c h}=n_{c b}+n_{\text {trap }}\right)$, which is equivalent to the charging of two chemical capacitor connected in parallel (i.e. $C_{c h}=C_{c b}+C_{\text {trap }}$ ). Since electrons captured by trap states in nanoporous $\mathrm{TiO}_{2}$ film are present at a much higher density than electrons in the conduction band, ${ }^{56,57}$ the total chemical capacitance density can be approximated by $C_{c h} \approx C_{\text {trap }} .{ }^{27,55}$ The resulting capacitive background current of nanostructured $\mathrm{TiO}_{2}$ films is therefore considered as governed by the filing of the distribution of traps in the bandgap, leading thus to an exponential dependence of the chemical trap capacitance with the voltage that varies as $\alpha F / R T \ln 10$ per decade (eq 10) $:^{37}$

$C_{c h} \approx C_{\text {trap }}=C_{\text {trap }, 0} \exp \left[-\alpha \frac{F}{R T}\left(E-E_{C B}\right)\right]$

with $C_{\text {trap }, 0}=\frac{\alpha F^{2}}{R T} d_{f} C_{e, t r a p}^{0}$

(where $C_{e, t r a p}^{0}$ is the maximal concentration of electrons that can be injected into the localized states of the semiconductive film). The total capacitive courant $\left(I_{C}\right)$ that takes into account the localized traps and a contribution from the series capacitance of the underlying ITO surface (characterized by $C_{I T O}$ ) can thus be expressed as:

$$
I_{C}= \pm \frac{\alpha F^{2} v}{R T} d_{f} C_{e, t r a p}^{0} \exp \left[-\alpha \frac{F}{R T}\left(E-E_{C B}\right)\right] \pm C_{I T O} v
$$

From the slope of $5.7 \mathrm{~V}^{-1}$ in Fig. 6A, a value of $\alpha=0.33$ was then inferred. Eq 11 is presumed to give a symmetric $\mathrm{CV}$ with a forward scan of opposite sign to the reverse one because of the sign reversal of $v$, but such an ideal behaviour is not reached experimentally (as observed in Fig. 6B or S8). Several factors can affect and distorts the shape and symmetry of the CV charging current. The occurrence of an unidentified charge transfer reaction taking place at the $\mathrm{TiO}_{2}$ /electrolyte interface has been previously reported to strongly affect the shape of the capacitive $\mathrm{CV}$ current of mesoscopic $\mathrm{TiO}_{2}$ films, especially at low scan rates. ${ }^{37}$ An analogous comportment is observed here at the slowest scan rates, where the forward charging current is abnormally increased at the expense of the reverse one which gradually disappears, leading thus to a highly dissymmetric CV plot. Increasing the scan rate is a way to minimize this faradaic contribution and so to recover (at least partially) a more symmetrical CV shape. This is typically what we observe in Fig. S8, but in spite of a certain degree of symmetry recovery at the highest scan rates, the forward and backward currents remain distorted. Among the other factors that significantly distort the shape of the capacitive $\mathrm{CV}$ current of $\mathrm{TiO}_{2}$ films is the resistance connected in series to the capacitance. ${ }^{37}$ This is evidenced in Fig. 6B or S8 where the anodic capacitive peak currents observed on the reverse scans suggest a delay in the return of the discharging currents down to the background currents. Distortion of the charging current by an ohmic drop has thus to be taken into account to correctly describe the shapes of CVs in Fig. 6. It may be achieved using the same procedure as the one proposed by Fabregat-Santiago et al. ${ }^{37}$ (recalled in SI). We have thus used this latter procedure to simulate and fit the experimental CVs recorded at the highest scan rates (i.e., $v=20,50$ and $100 \mathrm{mV} / \mathrm{s}$ ) (Fig. 6B) by iterative adjustment of the following three unknown parameters: $R_{S}$, $C_{t}=C_{\text {trap }, 0} \exp \left(-\alpha F E_{C B} / R T\right)$ and $\alpha$. From the best fits, the following values were finally obtained: $R_{S}=1500 \Omega, \alpha=0.32$, and $C_{t}=0.1 \mu \mathrm{F} / \mathrm{cm}^{2}$. The extracted value of $\alpha F /(R T \ln 10)=5.5$ $\mathrm{V}^{-1}$ was similar to the one roughly extracted from the slope in Fig. 6A, indicating that the impact of the series resistance on the determination of $\alpha$ is here not significant. Moreover, from the knowledge of $E_{C B}$ it is also possible to determine $C_{e, t r a p}^{0}$. Rothenberger et al. reported from spectroscopic studies the characteristic potential at which nanocrystalline films of $\mathrm{TiO}_{2}$ particles are brought into accumulation as a function of different $\mathrm{pH}^{58}$ This characteristic potential can be identified with the conduction band potential which, as a function of $\mathrm{pH}$, is given by $E_{C B}=-0.40-0.06 \mathrm{pH}$ (in $\mathrm{V} v s$. SCE) ${ }^{59}$ Under our experimental conditions ( $\mathrm{pH} 7.0$ ), we should thus have $E_{C B}=-$ $0.78 \mathrm{~V}$ (vs. $\mathrm{Ag} / \mathrm{AgCl})$ at $T=25^{\circ} \mathrm{C}$. Using this $E_{C B}$ value and $\alpha=$ 0.32 , a value of $C_{e, t r a p}^{0}=70 \mathrm{mM}$ (i.e., $4 \times 10^{19} \mathrm{~cm}^{-3}$ ) is found, which is finally close to the ones previously reported (1-2.5 $\times$ $10^{19} \mathrm{~cm}^{-3}$ ) for mesoscopic films of $\mathrm{TiO}_{2}$ based on sintered nanoparticles. ${ }^{37,57}$

\section{Analysis and simulations of CVs and DCVAs in the presence of an adsorbed redox couple}

Based on our analysis of the background current, indicating that the electron transport by diffusion in EISA $\mathrm{TiO}_{2}$ film is not rate limiting, analytical solution of the set of reaction-diffusion equations could be obtained ( situation, the total current is the sum of a faradaic component $I_{f}$ related to the redox transformation of the adsorbed dye and an apparent capacitive component $I_{C}$ being the sum of a term 
associated to the injection of free electrons in the $\mathrm{TiO}_{2}$ matrix, leading very rapidly to a uniform concentration of electrons throughout the film, and a term associated to the series capacitance of the underlying ITO surface. As show in the previous part, the absence of electron gradient due to the fast diffusion of electrons through the film means that $I_{C}$ is expressed by eq 11 . The advantage of spectroelectrochemistry is to permit to visualize only the faradaic component, which is the reason why only derivation of equations leading to the current $I_{f}$ has been considered below. This faradaic current component is the sum of two components: $I_{f, 1}$ associated with the reduction of species $\mathrm{O}$ directly at the $\mathrm{TiO}_{2}$ interface and $I_{f, 2}$ $=I_{p h}$ which corresponds to the faradaic contribution arising from the electrochemical transformation of the redox probe adsorbed into the film at the uncovered underlying ITO electrode. On the basis of our analysis of the capacitive current which clearly evidences the presence of localized states in the bandgap of the semiconductor, one would like to complete the model with a heterogeneous electron transfer reaction between the electrons trapped in localized states and the adsorbed redox probe. However, as it will be shown later on, such an electron transfer pathway appears in fine inoperative under our experimental conditions.

Considering a CV or DCVA performed at high enough potentials (i.e., in a potential window where $\mathrm{TiO}_{2}$ is insulating) and a redox systems that satisfy $E_{\mathrm{O} / \mathrm{R}}^{0} \gg E_{C B}$, we can write that $C_{e}=C_{e}^{0} \exp \left[-F / R T\left(E-E_{C B}\right)\right] \rightarrow 0 \quad$ and so $I_{f, 1} \rightarrow 0 \quad$ and $I_{f}=I_{f, 2}$. The resulting set of equations describing the system is exactly the one corresponding to a reversible one-electron wave with slow electron transfer, characteristic of a redox couple confined in a finite thin layer (see SI). The wave is therefore governed by two dimensionless parameters: $l=d_{f} / \sqrt{D R T / F v}$ and $\Lambda=k^{0} \sqrt{R T / F v D}$ (see SI). At low scan rate $(l \rightarrow 0$ and $\Lambda \rightarrow \infty)$ a reversible adsorption wave proportional to $v$ is expected, whereas at a higher scan rate ( $l \rightarrow \infty$ and $\Lambda \rightarrow 0$ ), a diffusive slow electron transfer wave is foreseen. These conditions thus correspond to the first reversible cathodic wave observed on the CVs and CVAs of FeTMPyP (Fig. 4 and 5).

Let us now considering the case of a $\mathrm{CV}$ performed within a potential window where $\mathrm{TiO}_{2}$ is becoming increasingly conductive, we may thus find some conditions where the reduction rate of $\mathrm{O}$ by diffusion to the conductive ITO electrode is low compared to the reduction rate of $\mathrm{O}$ through the conduction band of $\mathrm{TiO}_{2}$. Therefore the consumption of $\mathrm{O}$ due to the first reduction wave can be considered as small and negligible, and so $I_{f, 2} \rightarrow 0$ and $I_{f}=I_{f, 1}$. Under these conditions, the system is governed by the following two dimensionless parameters $l=d_{f} / \sqrt{D R T / F v}$ and $\lambda \gamma=k C_{e}^{0} R T / F v$ (see SI). Unfortunately, it is not possible to get an analytical expression for $I_{f, 1}$ in the general case, but if we consider the following additional limiting case for which $l \rightarrow \infty$, we obtain (see SI):

$$
\begin{aligned}
\phi_{f}=\frac{I_{f}}{F}=\frac{I_{f, 1}}{F}= & k C_{e}^{0} C_{\mathrm{O}}^{0} d_{f} \exp \left[-\frac{F}{R T}\left(E-E_{C B}\right)\right] \\
& \exp \left\{-\frac{R T}{F v} k C_{e}^{0} \exp \left[-\frac{F}{R T}\left(E-E_{C B}\right)\right]\right\}
\end{aligned}
$$

(where $C_{\mathrm{O}}^{0} d_{f}=\gamma_{\mathrm{O}}^{0}$ ). A graphical representation of eq 13 leads to an irreversible asymmetric reduction peak, with a peak potential position, $E_{p}$, function of the scan rate and $k C_{e}^{0}$ :

$E_{p}=E_{C B}+\frac{R T}{F} \ln \left(\frac{R T}{F v} k C_{e}^{0}\right)$

and a peak maximum, $I_{f, p}\left(\right.$ or $\left.\phi_{f, p}\right)$, linearly proportional to $v$ and $\gamma_{\mathrm{O}}^{0}$ :

$\phi_{f, p}=\frac{I_{f, p}}{F}=\frac{F^{2}}{R T} v \gamma_{\mathrm{O}}^{0}$

In summary, in the context of fast electron diffusion in $\mathrm{TiO}_{2}$ and $E_{\mathrm{O} / \mathrm{R}}^{0} \gg E_{C B}$, two waves are expected in CV and DCVA. The first one corresponds to the direct reduction of $\mathrm{O}$ to the underlying conductive electrode. Analysis of this wave gives information on the film diffusion coefficients of $\mathrm{O}$ and $\mathrm{R}$ as well as on the heterogeneous electron transfer rate constant $k^{0}$ at the uncovered underlying conductive surface. The second wave corresponds to the reduction of the redox probe by the free electrons injected in $\mathrm{TiO}_{2}$. Analysis of this irreversible wave allows to extract the parameter $k C_{e}^{0}\left(\mathrm{~s}^{-1}\right)$ corresponding to the first order electron transfer rate constant between conduction band electrons in $\mathrm{TiO}_{2}$ and $\mathrm{O}$ adsorbed at the nanoporous semiconductive interface. It may also give information on the diffusion coefficient of $\mathrm{O}$ but unless the limiting case $l \rightarrow \infty$ is reached.

\section{Application of the model to EISA $\mathrm{TiO}_{2}$ electrodes loaded with MP-11 and FeTMPyP}

In the framework of DCVA, numerical resolution of reactiondiffusion equations given in the SI, using an appropriate set of parameters, should allow to calculate the flux $\phi_{f}=I_{f} / F$ as a function of potential and thus to reproduce the experimental data in Fig. 5 obtained either for a FeTMPyP- or MP-11-loaded EISA $\mathrm{TiO}_{2}$ electrode. For such a purpose, we have used the commercial DigiElch software dedicated to the simulation of electrochemical processes at electrode by finite difference computation $^{48}$ (see Experimental section for details).

In the case of a FeTMPyP-loaded electrode, as expected, two waves are observed on the simulations, the first one being reversible and the second one irreversible. The fitting of the data by simulations (red curves in Fig. 5) is very good using the following single set of parameters: $k^{0}=5 \times 10^{-7} \mathrm{~cm} \mathrm{~s}^{-1}, \beta=0.5$, $D_{O}=5 \times 10^{-12} \mathrm{~cm}^{2} \mathrm{~s}^{-1}, D_{R}=3 \times 10^{-11} \mathrm{~cm}^{2} \mathrm{~s}^{-1}$ and $k C_{e}^{0}=8 \times 10^{4}$ $\mathrm{s}^{-1}$. The absolute values of $D_{O}$ and $D_{R}$ were both consistent with those determined by chronoabsorptometry (Fig. 3 and Table 1). Using these values of $D_{O}$ and $D_{R}$, and the scan rates values used for the experiments, the calculation of $l$ leads to a dimensionless parameter ranging from 1 to 14 . Such a result 
indicates that at the slower scan rates the reversible wave centred on the standard potential of FeTMPyP is only partially controlled by the physical diffusion of the redox dye throughout the semiconductive film. The simulated DCVAs in Fig. 5 are also able to well-reproduce the fast growth of the second irreversible cathodic wave (located at $\sim-0.47 \mathrm{~V}$ ) with the increase of the scan rate, and this at the expense of the first reversible wave which tends to disappeared. The shape and position of the second irreversible cathodic wave are also quite well reproduced by simulation whatever the value of $v$.

Since the mass transport of MP-11 by physical diffusion across the film could be considered as inexistent (signifying that $I_{f, 2} \rightarrow 0$ ), it was interesting to analyse the data using the analytical expression given by eq 12 . This equation is valid for a redox couple that has a standard potential far away downward to the conduction band potential $\left(E_{\mathrm{O} / \mathrm{R}}^{0}>>E_{C B}\right)$ and for $l \rightarrow \infty$ (which is the case for the quasi-immobile MP-11, i.e. $D \rightarrow 0$ ), leading thus to a characteristic irreversible adsorption wave proportional to $v$ (verified experimentally by the fact that the irreversible DCVA peak of MP-11 in Fig. S7 is a linear function of $v$, at least for the slowest scan rates where distortion of the peak current by ohmic drop remains negligible). The best fits of eq 12 to the experimental cathodic waves of MP-11 in Fig. 5 were obtained from the knowledge of the experimental surface concentrations, $\gamma_{\mathrm{O}}^{0}$, the value of $E_{C B}=-0.78 \mathrm{~V}$ and by adjusting the unknown parameter $k C_{e}^{0}$. A value of $k C_{e}^{0}=8 \times$ $10^{3} \mathrm{~s}^{-1}$ was finally obtained. Although the fitting of eq 12 to the experimental data was nearly perfect for the slow scan rates, it was observed to deviate at the fastest scan rates. We have attributed this effect to the ohmic drop resulting from the series resistance that was previously identified from the analysis of the background $\mathrm{CV}$ capacitive current. In order to take into account this effect, we have numerically simulated the CVA using the same DigiEch procedure as used with FeTMPyP, except that we have included to the simulation an adjustable series resistance and considered MP-11 as immobile within the film (i.e., using a very low value of $D_{O}$ and $D_{R}$ in DigiElch). Under these conditions, an improved fitting of the forward cathodic scan (blue curves in Fig. 5) was finally obtained using an adjusted series resistance of $R_{S}=1000 \Omega$ and the same $k C_{e}^{0}$ value as before (i.e., $8 \times 10^{3} \mathrm{~s}^{-1}$ ). This resistance value is finally very close to the uncompensated resistance determined previously from the analysis of the background current at a free-heme EISA $\mathrm{TiO}_{2}$ electrode $\left(R_{S}=1500 \Omega\right)$, a result which illustrates the high self-consistency of our analysis.

If we would like here to consider a possible electron transfer operating predominantly via the distribution of localized states and not via those of the conduction band, the limiting case expressed by eq 12 has thus to be replaced by eq 15 (see SI) which includes the characteristic parameter $\alpha$ linked to the distribution of traps.

$$
\begin{aligned}
\phi_{f}=\frac{I_{f}}{F}=\frac{I_{f, 1}}{F}= & k C_{e}^{0} C_{\mathrm{O}}^{0} d_{f} \exp \left[-\alpha \frac{F}{R T}\left(E-E_{C B}\right)\right] \\
& \exp \left\{-\frac{R T}{F v} k C_{e}^{0} \exp \left[-\alpha \frac{F}{R T}\left(E-E_{C B}\right)\right]\right\}
\end{aligned}
$$

This equation was however unable to correctly fit the irreversible peak of MP-11 using a $\alpha$ value of 0.33 (Fig. S9), a result which finally demonstrates that, under our conditions, there is no significant interfacial electron transfer between the redox active dye and the distribution of localized traps on the surface of EISA $\mathrm{TiO}_{2}$, and so that electron transfer from the conduction band is the dominant mechanism. Such a behaviour may be explained by a peculiarly low density of surface states in EISA $\mathrm{TiO}_{2}$ films (seemingly much lower than in nanocrystalline film of sintered $\mathrm{TiO}_{2}$ nanoparticles), therefore rendering negligible their contribution to the overall charge transfer.

The very good fitting of the overall simulated CVs to the experimental ones, for both FeTMPyP and MP-11, finally strongly support our simple model. It also reveals that the interfacial electron transfer between the adsorbed redox dye and the semiconductive material is exclusively governed by electrons in the conduction band and not by electrons trapped in localized states. This is a significant result that contrasts with the interfacial charge transfer recombination mechanisms in dye-sensitized solar cells, ${ }^{60,61}$ for which localized states of $\mathrm{TiO}_{2}$ are assumed to participate in recombination between photoinjected electrons and oxidized species in the electrolyte. It was even proposed with dye-sensitized solar cell that the electron transfer between the acceptor in the electrolyte and traps localized in the bandgap takes place at surface traps physically localized either at the semiconductor/electrolyte interface or within a tunnelling distance from it. In this case, modeling the interfacial electron transfers requires to distinguish internal traps localized in the bulk of $\mathrm{TiO}_{2}$ (so theoretically unable to act as electron transfer centers) from those localized at the surface. ${ }^{31,32,62,63}$

Following nonadiabatic electron-transfer theory, the interfacial rate of electron transfer between a n-type semiconductor and an electron acceptor is given by the MarcusGerischer model (eq 16). ${ }^{64}$

$k C_{e}^{0}=A \exp \left\{-\frac{\left[\lambda-F\left(E_{\mathrm{O} / \mathrm{R}}^{0}-E_{C B}\right)\right]^{2}}{4 \lambda R T}\right\}$

where $\lambda$ is the reorganization energy (in $\mathrm{eV}$ ) and $A$ is a preexponential factor which depends both on the distance over which the electron transfer occurs and an appropriate frequency factor. From the classical-based collision theory, a preexponential factor value of $10^{-17} \mathrm{~cm}^{4} \mathrm{~s}^{-1}$ has been estimated for a bimolecular charge transfer process at a semiconductor/liquid interface. ${ }^{65}$ Such a value can be easily converted in a first order rate by taking into account the density of states in the conduction band of $\mathrm{TiO}_{2}$ (i.e. $N_{C} \sim 10^{18}$ donors per $\mathrm{cm}^{-3}{ }^{65,66}$ ) as 


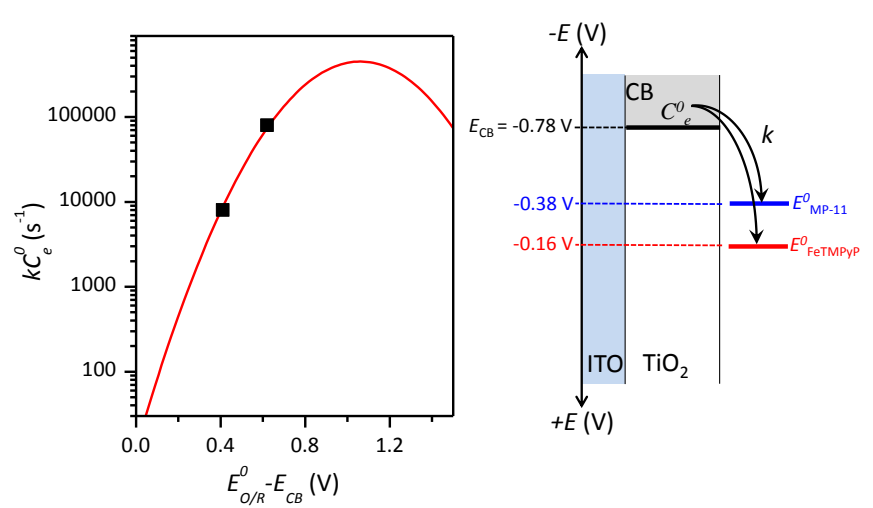

Fig. 7. (Left) Plot of the heterogeneous electron transfer rate as a function driving force. Red curve: fit of eq 16 to the data using $A=4.5 \times 10^{5} \mathrm{~s}^{-1}$ and $\lambda=$ $1.06 \mathrm{~V}$. (Right) Energy diagram of the relevant interfacial electron transfer processes.

well as the film thickness $\left(d_{f}=220 \mathrm{~nm}\right)$. A pre-exponential factor $A$ of $4.5 \times 10^{5} \mathrm{~s}^{-1}$ can thus be calculated. From the knowledge of $A$ and the adjustment of the parameter $\lambda$, the theoretical plot of eq 16 could thus be fitted to the values of $k C_{e}^{0}$ determined for each of the porphyrin-based compound as a function of the driving force (expressed by $E_{\mathrm{O} / \mathrm{R}}^{0}-E_{C B}$ ) (Fig. 7). From the best fit, a reorganization energy of $\lambda=1.06 \mathrm{~V}$ was obtained, a value which is consistent with the large reorganization energies previously found for a range of different redox couples at semiconductive materials. ${ }^{67}$ It is obvious that the only two experimental data on the graph of Fig. 7 (solely located on the normal Marcus region) is a too scarce number for accurately describing the overall MarcusGerischer plot with its inverted region, but one could easily imagine completing the data with a series of different redoxactive porphyrin couples having different standard potentials. This is a very appealing feature of the present methodology which thus offers a simple way to extract important information on electron transfers at nanoporous semiconductive materials, as well as a unique approach to access the inverted Marcus region and to determine reorganization energies of electron transfer reactions between absorbed redox-active molecules and a semiconductive material. This is also an important aspect of dye-sensitized solar cells where the detrimental recombination reactions between the photoinjected electrons in $\mathrm{TiO}_{2}$ and the adsorbed oxidized dye and/or the redox mediator in the electrolyte typically stem from reductive interfacial electron transfer processes. A better understanding of these mechanisms is therefore an essential step for improving the dye-sensitized solar cell performances. ${ }^{68}$ The possibility to explore the driving-force dependence for the interfacial charge transfer rate is an additional attractive feature of the present approach. It would notably help to understand the effect of the inverted Marcus region on the back electron transfer recombination reactions in dye-sensitized $\mathrm{TiO}_{2}$ solar cells, and so would contribute to clarify some of the conflicting results in literature. ${ }^{21,67}$

\section{Conclusions}

In the present study, we demonstrated that cyclic voltabsorptometry and chronoabsorptometry were especially well suited for characterizing qualitatively and quantitatively the charge transfer/transport in nanostructured semiconducting films loaded with redox-active molecules. This is particularly true for cyclic voltabsorptometry which permits to easily distinguish redox-active molecules that are involved in a conduction band mediated electron transfer from those that are associated to physical (and/or electron hoping) diffusion across the film up to the underlying conductor. Another important advantage of cyclic voltabsorptometry is the absence of charging current, allowing thus for a better insight into the reduction/oxidation mechanism of the redox dye in the film. The methodology also offers a unique and simple way to determine the dynamic of the heterogeneous charge transfer from the semiconductive film to a redox probe. According to eq 13 , this can be very easily achieved from the location of the irreversible DCVA reduction peak arising from the dye reduction through the conduction band. Furthermore, with the determination of the heterogeneous rates for a range of outersphere redox couples there is a route to explore the activationdriving force relationship according to the Marcus theory and then to determine if the redox probes fall into the normal or inverted region. This latter opportunity would be useful for investigating the driving-force effects on electron recombination dynamics in dye-sensitized solar cells and so to provide guidelines for improvement of the performance of the dye-sensitized solar cells.

Another important information that can be retrieved from the analysis of DCVAs is an identity of the nature of the conductive states involved in the interfacial electron transfer. In the present work, our results clearly suggests an electron transfer pathway predominantly governed by the extended states of $\mathrm{TiO}_{2}$, a behaviour that was attributed to a peculiarly low density of localized surface states in EISA $\mathrm{TiO}_{2}$. It would be then now interesting to investigate by cyclic voltabsorptometry different types of nanostructured $\mathrm{TiO}_{2}$ films with different density of localized surface states and then to examine their contribution and significance in the reduction rate of diverse redox couples adsorbed in these films. Such a study would be useful not only to better understand the charge recombination reactions occurring in dye-sensitized solar cells, but also to realize dye-sensitized solar cells with improved efficiencies (it would be achieved with the screening of metal oxide materials or morphologies for the photoanode that would alleviate the deleterious surface state mediated recombination). ${ }^{68}$ Another field where the present methodology is anticipated to be useful is in the mechanistic studies of heterogeneous photoelectrocatalytic systems, in particular those based on nanostructured semiconductor electrodes incorporating heterogeneous redox-active catalysts. ${ }^{69}$ Work is ongoing in our laboratory to address all of these matters.

\section{Acknowledgements}


The authors thank Dr. Claude Andrieux for fruitful discussions. This work was supported by Agence National pour la Recherche (ANR 3D-BIOELEC).

${ }^{a}$ Laboratoire d'Electrochimie Moléculaire, UMR 7591 CNRS, Université Paris Diderot, Sorbonne Paris Cité, 15 rue Jean-Antoine de Baiff, F-75205 Paris Cedex 13, France. E-mail : limoges.benoit@univ-paris-diderot.fr; Fax: +33157278788 ; Tel: +33157278789 .

${ }^{b}$ Laboratoire de Chimie de la Matière Condensée de Paris, UMR 7574 CNRS, UPMC-Paris 6-Collège de France, 11, place Marcelin Berthelot, 75231 Paris Cedex 05, France.

Electronic Supplementary Information (ESI) available: Figures S1-S9 and mathematical description and derivation of the model. See DOI: $10.1039 / \mathrm{b} 000000 \mathrm{x} /$

\section{Notes and references}

1. (a) B. C. O'Regan and M. Grätzel, Nature, 1991, 353, 737-40. (b) A. Hagfeldt and M. Grätzel, Acc. Chem. Res., 2000, 33, 269-77. (c) A. Hagfeldt, G. Boschloo, L. Sun, L. Kloo and H. Pettersson, Chem. Rev., 2010, 110, 6595-663. (d) B. C. O'Regan and J. R. Durrant, Acc. Chem. Res., 2009, 42, 1799-808.

2. (a) A. Heller, Acc. Chem. Res., 1995, 28, 503-8. (b) S. Asaftei and L. Walder, Langmuir 2006, 22, 5544-7. (c) C. Chen, J. J. Conception, J. W. Jurss and T. J. Meyer, J. Am. Chem. Soc., 2009, 131, 15580-1.

3. (a) O. K. Varghese, D. W. Gong, M. Paulose, K. G. Ong and C. A. Grimes, Sens. Actuators B, 2003, 93, 338-44. (b) E. Topoglidis, A. E. G. Cass, G. Gilardi, S. Sadeghi, N. Beaumont and J. R. Durrant, Anal. Chem., 1998, 70, 5111-3. (c) R. Md. Mahbubur, A. A. J. Saleh, J. Joon-Hyung, A. Sang Jung and L. Jae-Joon, Sensors, 2010, 10, 4855-86.

4. (a) F. Campus, P. Bonhôte, M. Grätzel, S. Heinen and L. Walder, Sol. Energy Mater. Sol. Cells, 1999, 56, 281-97. (b) D. Cummins, G. Boschloo, M. Ryan, D. Corr, S. N. Rao and D. Fitzmaurice, J. Phys. Chem. B, 2000, 104, 11449-59. (c) S. Y. Choi, M. Mamak, N. Coombs, N. Chopra and G. A. Ozin, Nano Lett., 2004, 4, 1231-5. (d) Q. Wang, S. M. Zakeeruddin, J. Cremer, P. Bäuerle, R. HumphryBaker and M. Grätzel, J. Am. Chem. Soc., 2005, 127, 5706-13. (e) N. Vlachopoulos, J. Nissfolk, M. Möller, A. Briançon, D. Corr, C. Grave, N. Leyland, R. Mesmer, F. Pichot, M. Ryan, G. Boschloo and A. Hagfeldt, Electrochim. Acta,, 2008, 53, 4065-71.

5. (a) D. Da, K. M. Gyu, L. J.; Yang and C. Jaephil, Energ. Environ. Sci., 2009, 2, 818-37. (b) J-H. Kim, K. Zhu, Y. Yan, C. L. Perkins and A. J. Frank, Nano lett., 2010, 10, 4099-104.
6. The nanostructured $\mathrm{TiO}_{2}$ films are generally obtained from a sintered film of $\mathrm{TiO}_{2}$ nanoparticles deposited on a glass substrate coated with an indium thin oxide layer.

7. J. Bisquert, Phys. Chem. Chem. Phys., 2008, 10, 49-72.

8. It has been shown that an electron concentration of $2.4 \times 10^{17} \mathrm{~cm}^{-3}$ in $\mathrm{TiO}_{2}$ should corresponds to a specific conductivity of $1.6 \times 10^{-4} \mathrm{~S} \mathrm{~cm}^{-}$

1 if a value of $10^{-4} \mathrm{~cm}^{2} \mathrm{~s}^{-1}$ is used for the electron diffusion coefficient. M. Grätzel, Inorg. Chem., 2005, 44, 6841-51.

9. (a) C. P. Andrieux and J. M. Savéant, J. Electroanal. Chem., 1980, 111, 377-81. (b) F. C. Anson, D. N. Blauch, J. M.; Savéant and C. F. Shu, J. Am. Chem. Soc., 1991, 113, 1922-32. (c) D. N. Blauch and J. M. Savéant, J. Am. Chem. Soc., 1992, 114, 3323-2. (d) D. N. Blauch and J. M. Savéant, J. Phys. Chem., 1993, 97, 6444-8.

10. (a) E. Laviron, J. Electroanal. Chem., 1980, 112, 1. (b) E. Laviron, L. Roullier and C.; Degrand, J. Electroanal. Chem., 1980, 112, 11-23.

11. (a) H. Dahms, J. Phys. Chem., 1968, 72, 362-5. (b) I. Ruff and V. J. Friedrich, J. Phys. Chem., 1971, 75, 3297-302.

12. Q. Wang, S. M. Zakeeruddin, M. K. Nazeeruddin, R. Humphry-Baker and M. Grätzel, J. Am. Chem. Soc., 2006, 128, 4446-52.

13. X. Li, M. K. Nazeeruddin, M. Thelakkat, P. R. F. Barnes, R. Vilar and J. R. Durrant, Phys. Chem. Chem. Phys., 2011, 13, 1575-84.

14. S. A. Trammell and T. J. Meyer, J. Phys. Chem. B, 1999, 103, 104-7.

15. P. Bonhôte, E. Gogniat, S. Tingry, C. Barbé, N. Vlachopoulos, F. Lenzmann, P. Comte and M. Grätzel M. J. Phys. Chem. B, 1998, 102, 1498-507.

16. A. Solbrand, H. Lindström, H. Rensmo, A. Hagfeldt, S. -E. Lindquist and S. Södergren, J. Phys. Chem. B, 1997, 101, 2514-8.

17. K. Zhu, N. Kopidakis, N. R. Neale, J. van de Lagemaat and A. J. Frank, J. Phys. Chem. B, 2006, 110, 25174-80.

18. H. G. Agrell, G. Boschloo and A. Hagfeldt, J. Phys. Chem. B, 2004, 108, 12388-96.

19. A. J. Frank, N. Kopidakis and J. van de Lagemaat, Coord. Chem. Rev., 2004, 248, 1165-79.

20. K. D. Benkstein, N. Kopidakis, J. van de Lagemaat and A. J. Frank, J. Phys. Chem. B, 2003, 107, 7759-67.

21. S. Ardo and G. J. Meyer, Chem. Soc. Rev., 2009, 38, 115-64.

22. N. Kopidakis, E. A. Schiff, N. -G. Park, J. van de Lagemaat and A. J. Frank, J. Phys. Chem. B, 2000, 104, 3930-6.

23. J. Nelson, Phys. Rev. B, 1999, 59, 15374-80.

24. S. Kambe, S. Nakade, T. Kitamura, Y. Wada and S. Yanagida, $J$. Phys. Chem. B, 2002, 106, 2967-72.

25. J. Bisquert and A. Zaban, Appl. Phys. A 2003, 77, 507-14.

26. P. E. de Jongh and D. Vanmaekelbergh, Phys. Rev. Lett. 1996, 77, 3427-30. 
27. J. van de Lagemaat and A. J. Frank, J. Phys. Chem. B, 2000, 104, 4292-4.

28. A. C. Fisher, L. M. Peter, E. A. Ponomorev, A. B. Walker and K. G. U. Wijayantha, J. Phys. Chem. B, 2000, 104, 949-58.

29. M. J. Cass, A. B. Walker, D. Martinez and L. M. Peter, J. Phys. Chem. B, 2005, 109, 5100-7.

30. F. Cao, G. Oskam, G. J. Meyer and P. C. Searson, J. Phys. Chem. 1996, 100, 17021-7.

31. J. Bisquert, A. Zaban and P. Salvador, J. Phys. Chem. B, 2002, 106, 8774-82.

32. J. Bisquert, F. Fabregat-Santiago, I. Mora-Seró, G. Garcia-Belmonte and S. Giménez, J. Phys. Chem. C, 2009, 113, 17278-90.

33. F. Fabregat-Santiago, J. Bisquert, G. Garcia-Belmonte, G. Boschloo and A.; Hagfeldt, Sol. Energy Mater. Sol. Cells, 2005, 87, 117-31.

34. F. Fabregat-Santiago, G. Garcia-Belmonte, J. Bisquert, A. Zaban and P. Salvador, J. Phys. Chem. B, 2002, 106, 334-9.

35. A. L. Roest, J. J. Kelly and D. Vanmaekelbergh, Appl. Phys. Lett., 2003, 83, 5530-2.

36. A. Staniszewski, A. J. Morris, T. Ito and G. J. Meyer, J. Phys. Chem. B, 2007, 111, 6822-8.

37. F. Fabregat-Santiago, I. Mora- Seró, G. Garcia-Belmonte and J. Bisquert, J. Phys. Chem. B, 2003, 107, 758-68.

38. E. E. Bandcroft, J. S. Sidwell and H. N. Blount, Anal. Chem., 1981, 53, 1390-4.

39. (a) C. Renault, K. D. Harris, M. J. Brett, V. Balland and B. Limoges, Chem. Commun., 2011, 47, 1863-5. (b) C. Renault, C. P. Andrieux, R. T. Tucker, M. J. Brett, V. Balland and B. Limoges, J. Am. Chem. Soc., 2012, 134, 6834-45.

40. C. E. McNamee, Y. Tsujii and M. Matsumoto, Langmuir, 2005, 21, 11283-88.

41. D. Grosso, G. J. de A. A. Soler-Illia, E. L. Crepaldi, F. Cagnol, C. Sinturel, A. Bourgeois, A. Brunet-Bruneau, H. Amenitsch, P. A. Albouy and C. Sanchez, Chem. Mater., 2003, 15, 4562-70.

42. Y. Sakatani, D. Grosso, L. Nicole, C. Boissiere, G. J. de A. A. SolerIllia and C. Sanchez, J. Mater. Chem., 2006, 16, 77-82.

43. M. Etienne, D. Grosso, C. Boissière, C. Sanchez and A. Walcarius, Chem. Commun., 2005, 4566-8.

44. C. Renault, V. Balland, E. Martinez-Ferrero, L. Nicole, C. Sanchez and B. Limoges, Chem. Commun., 2009, 7494-6.

45. C. Sanchez, C. Boissière, D. Grosso, C. Laberty and L. Nicole, Chem. Mater., 2008, 20, 682-737.

46. P. A. Forshey and T. Kuwana, Inorg. Chem., 1981, 20, 693-700.

47. M. T. Wilson and R. J. Ranson, Eur. J. Biochem., 1977, 77, 193-9.

48. M. Rudolph, J. Electroanal. Chem., 2003, 543, 23-39.
49. P. A. Adams, D. A., Baldwin and H. M. Marques, in Cytochrome c: a multidisciplinary approach, eds. R. A. Scott, A. G. Mauk, University Science Books, Sausalito, California, 1996, pp. 635-92.

50. On the basis of a geometric model, a theoretical saturating surface coverage of $\Gamma_{\text {theo }}{ }^{\text {sat }}=7 \times 10^{-11} \mathrm{~mol} \mathrm{\textrm {cm } ^ { - 2 }}$ can be estimated for $[\text { FeTMPyP }]^{5+}$ when considering a molecular area of $236 \AA^{2}$ for a coplanar adsorption of the molecule to the surface, while a value of $\Gamma_{\text {theo }}^{\text {sat }}=3 \times 10^{-11} \mathrm{~mol} \mathrm{~cm}{ }^{-2}$ can be calculated for MP-11 taking the size of each MP-11 molecule along the projection of terminal amine to be $620 \AA^{2}$.

51. D. A. Van Galen and M. Majda, Anal. Chem., 1988, 60, 1549-53.

52. J. Jiang, A. Glidle and C. J. McNeil, J. M. Cooper, Biosens. Bioelectron., 1997, 12, 1143-55.

53. A. J. Bard and L. R. Faulkner, Electrochemical Methods. Fundamentals and Applications, John Wiley \& Sons Inc., 2001.

54. The model we propose here is a simplified one since it does not consider the possible heterogeneous electron transfers with localized states present in the bandgap of the semiconductor. Such an electron transfer pathway has not been taken into account for the reason that it has been observed in fine inoperative under our experimental conditions.

55. J. Bisquert and V. S. Vikhrenko, J. Phys. Chem. B, 2004, 108, 231322.

56. G. Schlichthörl, S. Y. Huang, J.; Sprague and A. J. Frank, J. Phys. Chem. B, 1997, 101, 8141-55.

57. G. Boschloo and D. Fitzmaurice, J. Phys. Chem. B, 1999, 103, 222831.

58. G. Rothenberger, D. Fitzmaurice and M. Grätzel, M. J. Phys. Chem., 1992, 96, 5983-6.

59. A. Hagfeldt and M. Grätzel, Chem. Rev., 1995, 95, 49-68.

60. L. M. Peter and K. G. U. Wijayantha, Electrochem. Commun.,1999, 12, 576-80.

61. P. Salvador, M. Gonzalez Hidalgo, A. Zaban and J. Bisquert, J. Phys. Chem. B, 2005, 109, 15915-26.

62. J. Bisquert, A. Zaban, M. Greenshtein, I. Mora-Seró, J. Am. Chem. Soc., 2004, 126, 13350-9.

63. J. A. Anta, J. Idigoras, E.; Guillén, J. Villanueva-Cab, H. J. Mandajunano-Ramírez, G. Oskam, L. Pellejà and E. Palomares, Phys. Chem. Chem. Phys., 2012, 14, 10285-99.

64. (a) R. A. Marcus, Rev. Mod. Phys., 1993, 65, 599-609. (b) H Gerischer, Electrochim. Acta, 1990, 35, 1677-99.

65. (a) N. S. Lewis, Annu. Rev. Phys. Chem. 1991, 42, 543-80. (b) N. S. Lewis, Solar Energy Materials and Solar Cells, 1995, 38, 323-5. 
66. M. C. K. Sellers and E. G. Seebauer, Thin Solid Films, 2011, 519, 2103-10.

67. (a) I. Martini, J. H. Hodak and G. V.; Hartland, J. Phys. Chem. B, 1998, 102, 607-14 (b) X. Dang and J. T. Hupp, J. Am. Chem. Soc., 1999, 121, 8399-400. (c) D. A. Gaal and J. T. Hupp, J. Am. Chem. Soc., 2000, 122, 10956-63. (d) D. Kuciauskas, M. S. Freund, H. B. Gray, J. R. Winkler and N. S.; Lewis, J. Phys. Chem. B, 2001, 105, 392-403. (e) . G. Ramakrishna, A. K. Singh, D. K. Palit and H. N.; Ghosh, J. Phys. Chem. B, 2004, 108, 1701-7. (f) S. M. Feldt, P. W. Lohse, F. Kessler, M. K. Nazeeruddin, M. Grätzel, G. Boschloo and A. Hagfeldt, Phys.Chem. Chem. Phys., 2013, 15, 7087-97.

68. J. W. Ondersma and T. W. Hamann, Coord. Chem Rev., 2013, 257, $1533-43$.

69. J. Yang, D. Wang , H. Han and C. Li, Acc. Chem. Res., 2013 46, 1900-9. 